\title{
Recent advances in design and applications of biomimetic self-assembled peptide hydrogels for hard tissue regeneration
}

\author{
Haniyeh Najafi ${ }^{1}$. Mahboobeh Jafari ${ }^{1}$. Ghazal Farahavar ${ }^{1}$. Samira Sadat Abolmaali ${ }^{1,2}$. Negar Azarpira ${ }^{3}$. \\ Sedigheh Borandeh ${ }^{2,4} \cdot$ Raheleh Ravanfar ${ }^{5}$ (I)
}

Received: 8 March 2021 / Accepted: 12 June 2021 / Published online: 20 July 2021

(c) This is a U.S. government work and not under copyright protection in the U.S.; foreign copyright protection may apply 2021

\begin{abstract}
The development of natural biomaterials applied for hard tissue repair and regeneration is of great importance, especially in societies with a large elderly population. Self-assembled peptide hydrogels are a new generation of biomaterials that provide excellent biocompatibility, tunable mechanical stability, injectability, trigger capability, lack of immunogenic reactions, and the ability to load cells and active pharmaceutical agents for tissue regeneration. Peptide-based hydrogels are ideal templates for the deposition of hydroxyapatite crystals, which can mimic the extracellular matrix. Thus, peptide-based hydrogels enhance hard tissue repair and regeneration compared to conventional methods. This review presents three major self-assembled peptide hydrogels with potential application for bone and dental tissue regeneration, including ionic selfcomplementary peptides, amphiphilic (surfactant-like) peptides, and triple-helix (collagen-like) peptides. Special attention is given to the main bioactive peptides, the role and importance of self-assembled peptide hydrogels, and a brief overview on molecular simulation of self-assembled peptide hydrogels applied for bone and dental tissue engineering and regeneration.
\end{abstract}

\section{Graphic abstract}

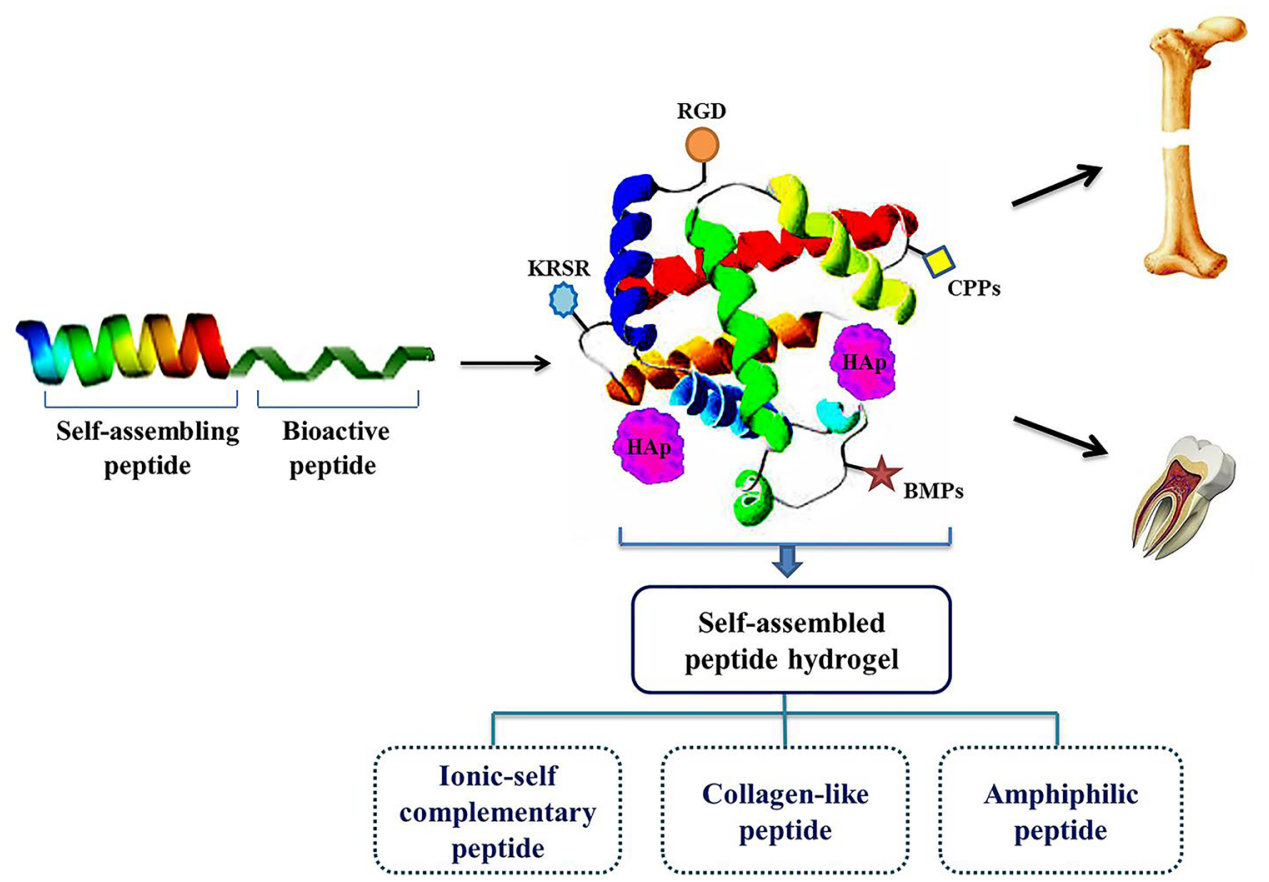

Keywords Self-assembled peptides $\cdot$ Hydrogel $\cdot$ Bone-repair material $\cdot$ Dental regeneration $\cdot$ Hard tissue engineering

Extended author information available on the last page of the article 


\section{Introduction}

Hard tissues such as bone and tooth (dentin, enamel, and cementum) are living and mineralized tissues with a high degree of hardness [1]. Bones generally show moderate selfcuring capability after fracture or defect, while osteoporosis can raise the rate of bone fractures due to population age. Dental caries are also one of the prevalent human diseases caused by acidic condition and can result in mineral loss and affect general health and life quality. Moreover, caries treatment usually fails over time as a result of secondary caries. Hard tissue regeneration imposes sizable healthcare costs on society, which may dramatically increase as the population ages. Thus, the development of suitable biomaterials for hard tissue repair and regeneration is an important task, especially for societies with a large elderly population [2]. So far, several biomaterials such as metal implants, allografts, autografts, ceramic, demineralized matrix, polymers, and composites have been applied for hard tissue regeneration [3-5]. Although conventional biomaterials like ceramics, bio-glass, and bone cement are significant for restoring hard tissues, they fail in promoting self-tissue regeneration, which is critical for healthy bones. Therefore, developing a new generation of biomaterials capable of serving as templates for hard tissue growth is an immense task $[2,6]$. Recently, various types of self-assembled hydrogels like nucleic acids, carbohydrates, and peptides have attracted a great deal of attention due to their valuable features such as biocompatibility, reversible disassembly, mechanical robustness, customizable functional behavior, and facile folding to form two-/three-dimensional biomimetic matrix [7, 8]. The selfassembled hydrogels are simply produced with a molecular self-assembly process. Molecular self-assembly is a spontaneous process in which the molecules assemble into a stable structure via non-covalent interactions, such as hydrogen bonding, electrostatic interactions, $\pi-\pi$ stacking, and hydrophobic interactions. It is indeed a bottom-up approach and a powerful technique for producing novel nanostructures and biomaterials [9]. Moreover, the formation of molecular selfassemblies can be triggered via external influences such as $\mathrm{pH}$, temperature, and electrolytes under physiological conditions [10]. Among self-assembled hydrogels, peptide-based self-assemblies have been considered promising candidates for several reasons $[11,12]$. (1) It is economic and facile to make them using a solid-phase peptide synthesizer. (2) The peptide hydrogel and final nanostructure can form under physiological conditions. (3) A desirable molecular structure can be obtained by tuning the peptide builder units. (4) Natural secondary structures of proteins (e.g., $\alpha$-helix and $\beta$-sheet) can be used to promote the self-assembly process $[13,14]$. Therefore, self-assembled peptide hydrogels are promising biomaterials with valuable advantages that can provide proper scaffolds for hard tissue self-curing and regeneration [15]. This review presents a discussion on the recent developments in self-assembled peptide hydrogels for bone and dental tissue regeneration. To this end, we will describe the principles of peptide design, different peptide self-assembling mechanisms, and their functionalities in Sects. "Self-assembly mechanism of peptide-based hydrogels", "Self-assembly mechanism of peptide-based hydrogels ". Molecular simulation also provides valuable information about the formation of self-assembled peptide hydrogels, which has been ignored in similar reviews [16, 17]. Therefore, we will give a brief overview of simulation approaches in Sect. "Self-assembly mechanism of peptidebased hydrogels ". Sections "Application of self-assembled peptide hydrogels in bone tissue regenerations", "Application of Self-assembled peptide hydrogels in dental tissue regeneration" are devoted to the role and importance of self-assembled peptide hydrogels in bone and dental tissue regeneration.

\section{Self-assembly mechanism of peptide-based hydrogels}

The power, elegance, and effectiveness of biological selfassembly have motivated scientists to exploit molecular self-assembly as a route to develop novel nanostructured materials for regenerative medicine and numerous biomedical applications. Of the various organic building blocks, peptides are one of the most valuable candidates for the generation of self-assembled nanostructures such as nanofibrils, nanorods, and nanotubes [18]. Over the past decades, several strategies have been developed to design supramolecular self-assembled peptides (SAPs). As shown in Fig. 1, different peptide-based nanostructures have been fabricated from five major categories (i.e., $\alpha$-helical/coiled coil peptides, elastin-like polypeptides (ELPs), cyclic peptides, $\beta$ - sheet peptides, and triple-helix peptides (collagen-like)) to design hierarchical self-assembled structures.

Alpha helical/coiled coil peptides or self-assembling fibers (SAFs) have been utilized to develop numerous fibrous biomaterials [19]. An SAF sequence is made of seven residues with (abcdefg) repeats and is known as a heptad. The "a" and "d" positions are occupied by hydrophobic residues (such as valine and leucine), while charged residues (lysine or glutamic acid) are located at positions "e" and "g" and are responsible for hydrophobic and electrostatic interactions. The residues at positions "b", "c", and "f" are exposed on the surface of assemblies and are often occupied by alanine or glutamine, which have a tendency to form hydrogen bonds. The configuration and stability of the coiled coil motifs depend on ionic strength, $\mathrm{pH}$, and temperature, which are 


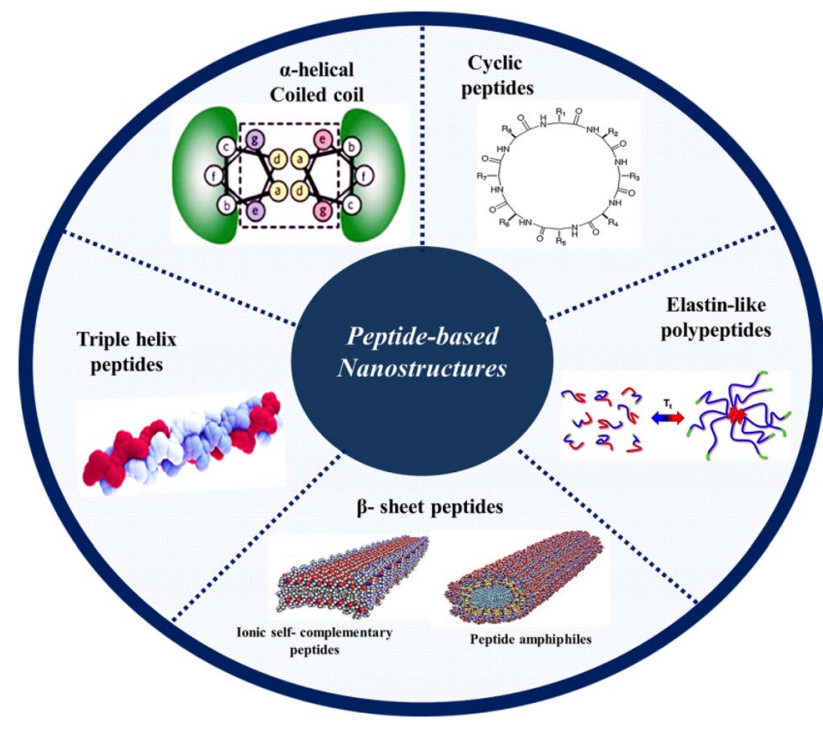

Fig. 1 Schematic presentation of major peptide-based nanostructures including $\alpha$-helical/coiled coil peptides, elastin-like polypeptides (ELPs), cyclic peptides, $\beta$-sheet peptides, and triple-helix peptides (collagen-like)

often exploited in stimuli-responsive systems [20]. Elastinlike polypeptides (ELPs) are a class of biopolymers derived from tropoelastin, which can self-assemble under certain physiological conditions. ELPs are composed of (VPGXG) $\mathrm{n}$ amino acid repeats, where the " $\mathrm{X}$ " position is a variable amino acid (except proline). The polarity of the "X" position regulates the transition temperature of the peptide. Upon raising the temperature beyond the transition temperature, these polypeptides display a transition from random coils to cylindrical micelles [21]. ELPs are attractive carriers due to their potential for local delivery of hydrophobic drugs through temperature-triggered coacervation. This targeted delivery approach is mainly valuable for prolonged local cancer therapy, where a solid tumor can be locally heated to trigger the ELP phase transition at the tumor site [22]. Peptide cyclization has been designed to offer rigidity, which allows the structure to adopt conformations that are not available in linear peptides. Increasing the conformational rigidity has been shown to improve receptor-binding affinity [23]. Cyclic peptides adopt flat conformations or stack via hydrogen bonding to form self-assembled peptide nanotubes, in which the amino acid side chains are oriented outward. These nanostructures can be used in biosensors, electronic devices, drug delivery, selective transport channels, and antimicrobial agents [24]. Hierarchical $\beta$-sheets are the most common natural motifs, with a dominant role in construction of peptide-based biomaterials and fabrication of supported scaffolds for three-dimensional cell culture and tissue regeneration [25]. They are categorized into several groups: self-complementary peptides [26], amphiphilic and surfactant-like peptides [27], $\beta$-sheet tapes [28], selfassembling $\beta$-hairpin peptides [29], various short peptides and aromatic derivatives [30]. These peptides spontaneously self-assemble into supramolecular nanofibers, nanotubes, or nanovesicles by intermolecular non-covalent bonding. Among $\beta$-sheet peptides, ionic self-complementary and amphiphilic peptides are ideal templates for the deposition of HAp crystals. Moreover, collagen-like peptides promote HAp growth and encapsulation due to their similarity to the fundamental component of the extracellular matrix (ECM) and collagen. Hence, this review is focused on the utilization of $\beta$-sheet peptides including ionic self-complementary, amphiphilic, and collagen-like peptides, and their functionalization as favorable three-dimensional biomaterial scaffolds for promoting bone and enamel regeneration. Other self-assembling peptides used to design functional biomaterial scaffolds have been extensively reported in previously published reviews [31-33].

\section{Ionic self-complementary peptides}

Among peptide nanostructures, ionic self-complementary peptides have shown great promise as biocompatible materials in hard tissue regeneration due to their 3D, well-organized pores sized between 5 and $200 \mathrm{~nm}$, which closely mimic the properties of ECM [24]. Ionic self-complementary peptides have alternating hydrophobic residues (e.g., alanine, valine, isoleucine, or phenylalanine) and hydrophilic residues with positive charges (e.g., lysine or arginine) or negative charges (e.g., aspartic or glutamic acids). These complementary co-assembled peptides (CAPs) are consequently formed due to the attractive and repulsive interactions between oppositely charged peptides. Depending on the charge distribution over the hydrophilic residue surfaces, ionic self-complementary peptides can be classified into four main moduli: (a) modulus I, ----++++ ; (b) modulus II, --++--++ ; (c) modulus III, -+-+-+-+ , (d) modulus IV, $----++++[34,35]$. Upon $\beta$-sheet formation (parallel or antiparallel) in aqueous media, charged hydrophilic residues face in one direction and hydrophobic residues face in the other direction in the hydrophobic inner pocket [36]. By adding electrolytes, the electrostatic repulsions between peptide monomers can be reduced, triggering self-assembly. Despite the strong tendency of these peptides to assemble into $\beta$-sheet nanostructures and interwoven nanofibers, depending on the number of $\beta$-sheet associations, various supramolecular structures such as ribbons, tapes, and fibrils can be also fabricated (Fig. 2) [37, 38].

One of the best-known ionic self-complementary peptides is RADARADARADARADA (RADA16-I or II), which has been commercialized as PuraMatrix ${ }^{\circledR}$. This sequence appears attractive for cell culture and cell attachment due to its similarity to the RGD sequence, which is known for 


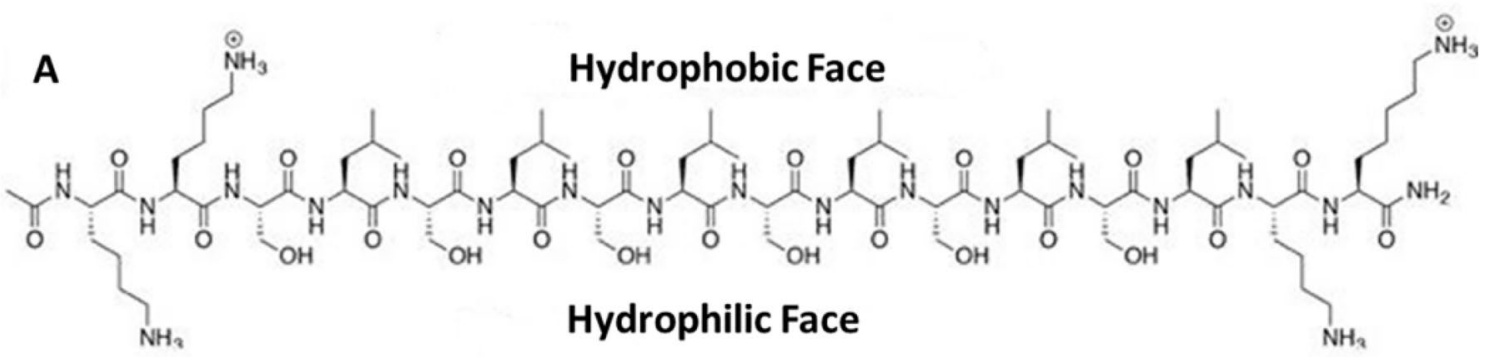

B

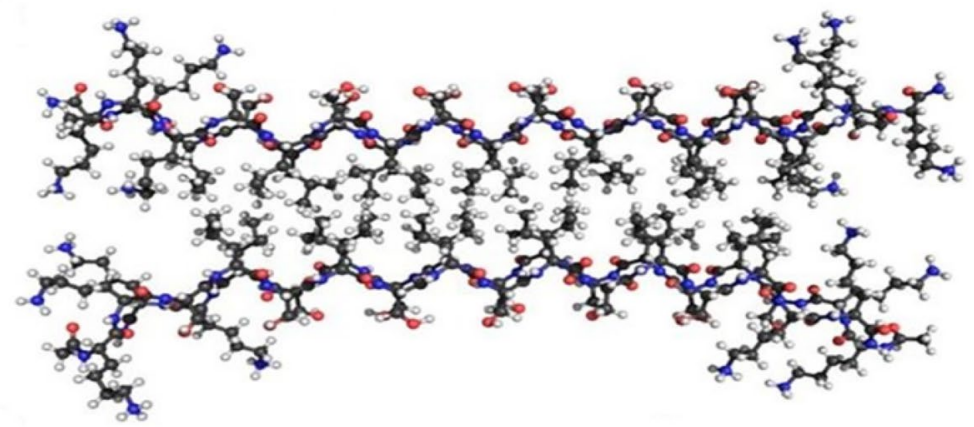

C

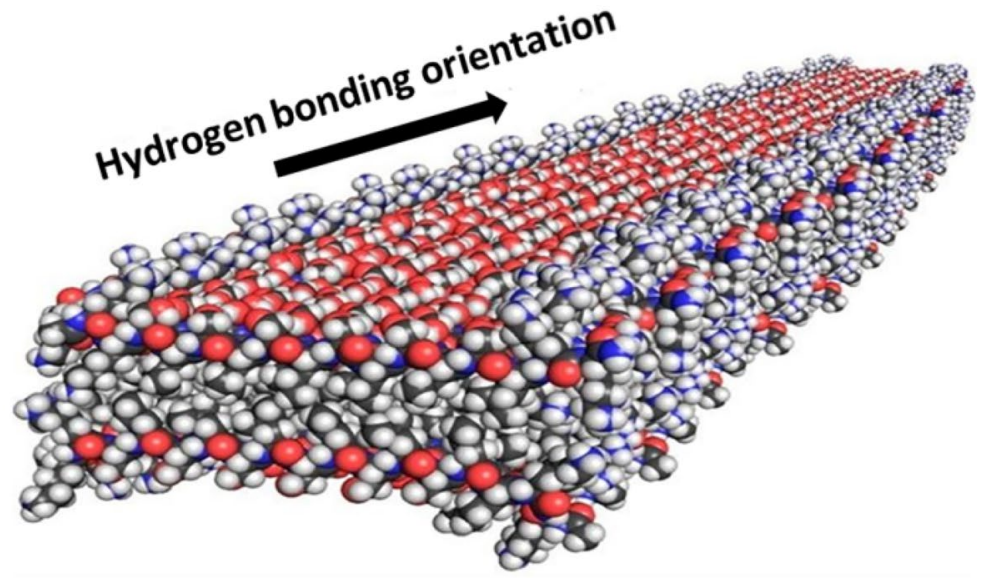

Fig. $2 \beta$-Sheet-forming self-assembling peptides with alternating ionic-complementary properties. General composition (a), primary sequence (b), and repeating unit of the peptide nanofiber (c) [39] (Reproduced with permission from Ref. [39] @ 2017 American Chemical Society)

its eminent cell adhesion properties [40]. Li et al. designed RADA16-I (modulus I) peptide-modified demineralized bone matrix (DBM) as an ideal 3D scaffold for MSCs in critically sized femur defects in goats. According to their results, in comparison with bare DBM, MSCs demonstrated better morphology and enhanced expression levels of alkaline phosphatase, runt-related transcription factor 2 (RUNX2), and osteocalcin (OCN) in DBM-modified selfassembled peptide hydrogel at day 14 . However, OCN and RUNX2 were not significantly different on day 7 due to the delayed release of osteogenic growth factors secreted by MSCs. Overall, they reported that the modified RADA16 scaffold had a significant impact in repairing 20-mm criticalsized defects in a goat model as compared to bare DBM [41]. The strength of ionic self-complementary peptides is still an issue in hard tissue regeneration. In this regard, Nakahara et al. synthesized a hybrid scaffold from polyetheretherketone (PEEK) cages, filled it with self-assembling peptide scaffold (RADA16), and transplanted it to bone defects in rat femurs. Due to the low strength of RADA16 for clinical bone regeneration applications, a PEEK cage with high intensity was used to stabilize the scaffold and provide the osteoconduction ability of ionic self-complementary peptide, which promoted bone formation inside the cage. After 28 days, according to gene expressions (e.g., ALP), soft $X$-ray radiographs, and histological findings, the PEEK cage with RADA16 showed better bone formation and higher strength than either the PEEK cage or peptide alone [42]. However, as these peptides were found to be capable of supporting cell attachment, the functionalization of RADA 
peptides is a good strategy for controlling cell behaviors, which we will discuss in more detail in the following sections [43].

\section{Collagen-like peptides}

Collagen is the main structural component of the extracellular matrix (ECM) and accounts for $25 \%-35 \%$ of human protein content. Till now, five major classes of collagens have been recognized. The three most common fibrous collagen types include type I, II, and III collagens located in bone, tendon, cartilage, ligament, and skin. Types IV and VIII play a pivotal role in the formation of fibrillar structures, including basement membranes [44]. Despite their immense architectural and functional differences, all these collagens comprise triple-helix bundles. The collagen triple helix has Glycine-X-Y tripeptide repeats, where $\mathrm{X}$ and $\mathrm{Y}$ generally represent proline and hydroxyproline, which are formed by periodic interchain hydrogen bonding [38]. In the past few decades, collagen-like (CLP) peptides, also known as collagen-mimetic peptides (CMP), have attracted much attention due to their unique structure and properties. Various CLPs have been designed not only to mimic natural collagen fibrils, but also to form highly ordered structures via $\pi-\pi$ stacking interactions, lateral electrostatic attraction, and metal-ion-triggered assembly to generate well-defined hierarchically self-organized nanostructures [45]. In a study, Pires et al. [46] designed a stimuli-responsive (metal-ionpromoted) collagen-like peptide with 5, 7, 9, and 11 ProHyp-Gly (POG) repeating units using a solid-phase synthesis method. They found that a range of morphologies, such as microflorettes, stacked sheet microsaddles, and fiber-like meshes could be achieved by changing the length of the collagen-like portion of the peptides. Collagen-like peptides, such as $\mathrm{NCoH} 5$, did not form a stable self-assembled peptide in the presence of $\mathrm{ZnCl}_{2}$; however, $\mathrm{NCoH} 9$ resulted in a microflorette shape with certain metals. Collagen peptides, such as NCoH11, assembled into microsaddle structures by metal-promoted assembly. However, a highly cross-linked, three-dimensional mesh was formed with $\mathrm{NCoH}$, especially at higher metal-ion concentrations (Fig. 3).

Regarding the limitations of native collagens, collagenlike peptides (CLPs) have been utilized as an alternative to improve thermal instability, cell adhesion, and proliferation, and prevent probable contamination with pathogens [47]. Krishna et al. [48] designed and developed a collagen-like peptide (CLP-Cys) sequence lacking hydroxyproline residue, which comprised the minimal required Gly-Glu-Arg (GER) triplet for supporting human mesenchymal stem cell (hMSC) adhesion, proliferation, and differentiation. The results showed that the hMSCs proliferated more on the CLP-Cys surfaces than on control surfaces in which CLP-Cys was not<smiles>CCC(=O)NC(Cc1c[nH]cn1)C(=O)NC(=O)CNC(=O)C1C[C@@H](O)CN1C(=O)C1CCCN1C(=O)CCC(C(=O)O)N(CC(=O)O)CC(=O)O</smiles>
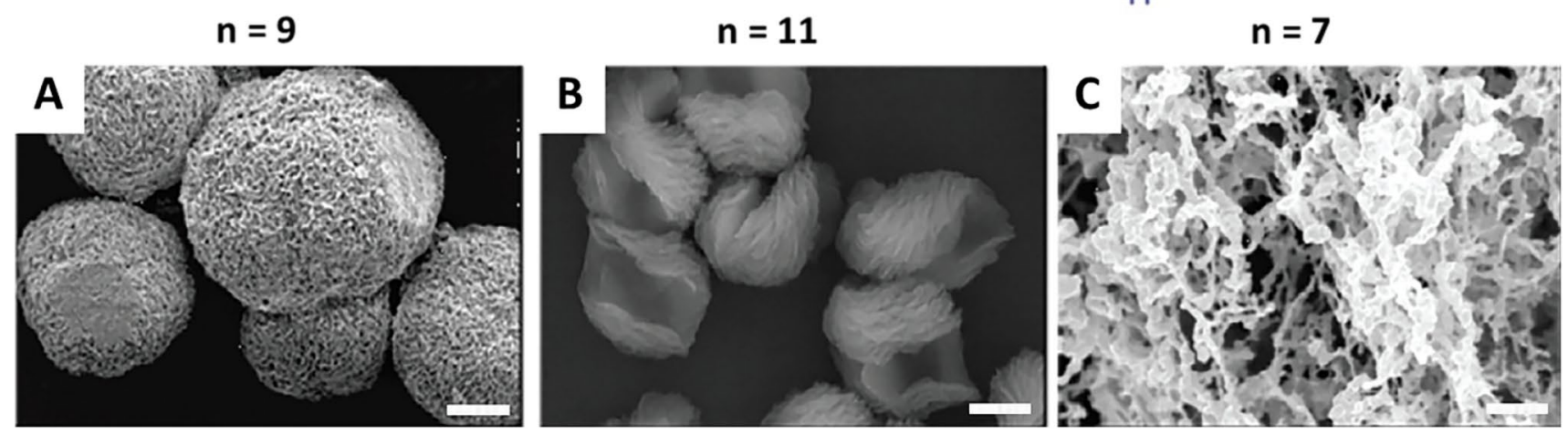

Fig. 3 SEM image of three collagen-like peptides with 7, 9, and 11 Pro-Hyp-Gly (POG) repeating units that generate various microstructures by a metal-mediated assembly strategy. Peptide NCoH5 did not assemble into a triple helix at room temperature. a Microflorette structures composed of $1 \mathrm{mM}$ NCoH9 with $400 \mu \mathrm{M}$ zinc chloride (II). b Saddle structures composed of $1 \mathrm{mM} \mathrm{NCoH} 11$ with $400 \mu \mathrm{M}$ zinc chloride (II). c Assemblies formed from $1 \mathrm{mM} \mathrm{NCoH7}$ with $1 \mathrm{mM}$ zinc chloride (II) kept in $\mathrm{pH} 7.4$ MOPS buffer at room temperature for $24 \mathrm{~h}$. Scale bar $=10 \mu \mathrm{m}$ for A, Scale bar $=3 \mu \mathrm{m}$ for B and Scale $\mathrm{bar}=2 \mu \mathrm{m}$ for C [46] (Reproduced with permission from Ref. [46] (C) 2012 American Chemical Society) 
present. Furthermore, blocking the $\alpha 2 \beta 1$ receptor on hMSC resulted in a decrement in the cell attachment on both types of CLP-Cys surfaces, either chemically conjugated to a hard glass or a soft hyaluronic acid (HA) particle-based hydrogel; this reflects the affinity of CLP-Cys to $\alpha 2 \beta 1$ receptors. Similar to type I collagen, CLP-Cys-modified HA scaffolds are promising bioactive hydrogels for hard tissue regeneration. Moreover, collagen-like peptides can form higher-order structures that mimic natural collagen fibers [49]. These peptides can be used as templates for the nucleation and growth of crystalline hydroxyapatite minerals in a sequenceand composition-dependent manner. The chemical formula $\mathrm{Ca}_{10}\left(\mathrm{PO}_{4}\right)_{6}(\mathrm{OH})_{2}$ represents HAps, which are calcium phosphate minerals accounting for approximately $65 \%$ of hard tissues. This compound is well recognized for its biocompatibility, osteoconductivity, non-toxicity, and bioactivity [50]. Chung et al. [51] synthesized a single-crystal HAp-binding peptide using computational modeling through phase display. The peptide sequence was responsible for the nucleation and growth of crystalline HAps in a sequence- and composition-dependent manner. These peptides were similar to the tripeptide repeat (Gly-Pro-Hyp) of type I collagen, which is known to be a major component of bone ECM. These short HAp-binding peptides may be useful in the synthesis of three-dimensional bone-like materials. To date, numerous studies have reported the fabrication of various CLP peptides for diverse applications, but further investigation is required into CLPs in hard tissue regeneration.

\section{Amphiphilic and surfactant-like peptides}

Another interesting approach to designing peptide nanostructures relies on the high aspect ratio of rods/cylinders. Due to the architectural resemblance of peptide amphiphile (PA) nanofibers to filamentous structures in natural mammalian extracellular matrices, they can function as a highly biomimetic artificial matrix. PAs are hybrids containing a peptide head covalently conjugated to single or multiple alkyl chains. Attaching peptides with self-assembly capability to amphiphilic surfactants offers very good control of nanostructure assembly into cylindrical or fibril geometries instead of micelles. The diameter and length of nanofibers can be tuned by the self-assembly conditions, number of charged amino acids, and lipid chain length [32]. Both hydrogen bonding and hydrophobic sequences facilitate peptide self-assembly into nanofiber or cylindrical geometries [52]. The self-assembly of peptide amphiphiles can be also triggered by $\mathrm{pH}$ or by adding an electrolyte to decrease the electrostatic repulsion [53]. One of the most important driving forces for biological self-association is hydrophobic interaction. In a study, Hartgerink et al. designed PAs capable of inducing mineralization of HAps to form a composite. This PA had five structural features: (1) hydrophobic domain (e.g., single or multiple alkyl chains), (2) four cysteine residues capable of forming disulfide bonds upon oxidation and contributing to polymerization of the self-assembled structure, (3) charged amino acids to improve water solubility and form pH- and salt-responsive structures, (4) a single phosphorylated serine residue designed for strong interaction with calcium ions and promotion of direct mineralization of Hap, and the functional head group (e.g., epitope peptides) to represent various bioactive motifs such as RGD or IKVAV for a better interaction with cell receptors [54].

Moreover, PAs are ideal templates for the deposition of HAp crystals because of their capability of mimicking the phosphoserine-rich motifs of dentin proteins. In particular, dentin matrix protein 1 (DMP1) is an acidic phosphoprotein present in bone and dentin and is highly involved in biomineralization. In this regard, Sargeant et al. [55] designed PA nanofibers incorporating phosphoserine residues which can promote HAp formation. In osteogenic medium supplemented with calcium, the PA nanofibers nucleated spheroidal nanoparticles of crystalline-carbonated HAp which were approximately $100 \mathrm{~nm}$ in diameter. To analyze the expression of osteogenic markers, quantitative real-time reverse transcription-polymerase chain reaction (QRT-PCR) was carried out. Based on immunohistochemistry analysis for ALP and osteopontin expression, the presence of phosphoserine residues in PA nanofibers appears to favor osteogenic differentiation.

\section{Bioactive peptides in hard tissue regeneration}

Modification of biomaterials with appropriate bioactive peptides could improve their functions. Particularly, it has been revealed that peptides modified with osteogenic-related repair materials can more efficiently promote the formation of new bone as compared with conventional peptides. Thus, various functional peptides have been studied and used as potential substances for promotion of hard tissue regeneration and defect repair [56]. In this section, we categorize these bioactive peptides into three main groups: (1) extracellular matrix (ECM)-derived peptides (ECM mimetic assemblies), (2) bone morphogenetic protein (BMP)-derived peptides (osteoinductive peptides), and (3) other peptides which will be briefly covered.

\section{ECM-derived peptides}

Extracellular matrix (ECM) is a complex molecular network in all tissues and organs which is involved in the development of biochemical and structural supports [57]. Although the different tissue types have different extracellular matrix compositions, the organic fraction of ECM hard tissue is 
commonly composed of three major components: (1) proteins similar to collagen type I, such as osteocalcin, osteopontin, and osteonectin, (2) multi-adhesive matrix proteins such as fibronectin, laminin, and vitronectin, and (3) proteoglycans like versican, decorin, or hyaluronan [58]. Most of these molecules have ligand sequences that can connect with specific cell receptors with important roles in the regulation of osteoblast and osteoprogenitor cell functions (e.g., attachment, migration, proliferation, and differentiation). Nevertheless, ECM-derived peptides with signaling domains have been extracted from ECM proteins due to their capability to recognize cell receptors like integrin.

Among ECM-derived peptides, the tripeptide Arg-GlyAsp, which belongs to the integrin supergene family, is one of the most studied ligands for biomedical functionalization due to its potent integrin recognition and binding domain. It mainly exists in various extracellular matrix proteins, such as fibronectin, vitronectin, bone sialoprotein, and osteopontin [59]. RGD peptide as a cell adhesion sequence can increase the expression of bone sialoprotein (BSP), osteopontin Runx2, ALP, and osteocalcin [60]. Thus, it can significantly promote osteoblast proliferation, differentiation, and mineralization, as well as enhancing cell attachment [61]. Meanwhile, many studies have reported the considerable effect of RGD in osteoprogenitor cell proliferation and/ or differentiation, but there are several limitations regarding the in vivo use of RGD in bone-related applications [62]. Oh et al. [63] studied the effects of RGD peptide-coated $\mathrm{TiO}_{2}$ nanotubes on the cellular response and functionality of osteogenic-induced human mesenchymal stem cells (hMSCs) by immobilizing RGD peptide on the surface of 30- and 100-nm $\mathrm{TiO}_{2}$ nanotubes. According to their results, this approach can accelerate the initial attachment of preosteoclasts and proliferation of mature osteoclasts, but shows no superiority for in vivo bone formation, as osteoblasts and osteoclasts reside in the same compartment. Anderson et al. [64] synthesized a bioactive peptide amphiphile with RGDS peptide to promote osteoconductivity. Compared to bare self-assembling peptide, the developed scaffolds could retain embedded HAp and induce osteogenic differentiation.

PepGen P-15 (P-15) contains 15 amino acid residues and has an identical makeup to the cell-binding site of collagen type I [65]. According to several reports, P15 can support hard tissue growth through stimulating human osteoblast differentiation and proliferation, enhancing cell attachment to bone-repair substitutes, and upregulating ECM production [66, 67]. Liu et al. [1] also covalently bonded P-15 to titanium alloy surfaces and incubated it with osteoblast-like cells. According to their results, surface modification with P15 significantly enhanced cell attachment, spreading, and differentiation. Furthermore, P-15 dramatically increased osteogenic gene expression, osteogenic ALP proteins, and matrix mineralization due to upregulating RUNX2, collagen
1, osterix, BSP, bone morphogenetic protein-2 (BMP-2), and bone morphogenetic protein-7 (BMP-7) in a human osteosarcoma cell line.

Interestingly, Ser-Val-Val-Tyr-Gly-Leu-Arg (SVVYGLR) peptide resembles the RGD sequence in osteopontin. It can promote the attachment and proliferation of MSCs as well as the upregulation of neovascularization [68]. Park et al. [69] synthesized an injectable hydrogel by conjugating the SVVYGLR peptide sequence to gelatin poly (ethylene glycol)-tyramine (GPT) hydrogel in the presence of horseradish peroxidase (HRP) and hydrogen peroxide $\left(\mathrm{H}_{2} \mathrm{O}_{2}\right)$. The results demonstrated that in situ conjugation of the SVVYGLR peptide to injectable GPT hydrogels influenced human umbilical vein endothelial cell (HUVEC) activity and stimulated angiogenic activity in the matrix.

Osteoblasts and osteoprogenitors express a wide variety of integrins, such as $\alpha 1 \beta 1$ and $\alpha 2 \beta 1$. Asp-Gly-Glu-Ala (DGEA) and Gly-Phe-Hyd-Arg (GFOGER) are collagenlike peptides capable of binding to $\alpha 2 \beta 1$ integrin. In addition, Arg-Arg-Glu-Thr-Ala-Trp-Ala (RRETAWA) is a specific ligand for $\alpha 5 \beta 1$ integrin. These peptide sequences can accelerate and improve osteoblastic differentiation, bone regeneration, and osseointegration [70, 71].

The collagen-binding motif (CBM) is a cleavage product of osteopontin which can specifically bind to collagen. CBMs can significantly enhance migration and osteogenic differentiation through the $\mathrm{Ca}^{2+} / \mathrm{CaMKII/ERK/activating}$ protein-1 signaling pathway. Moreover, in vitro experiments have demonstrated their great potential in the migration of human mesenchymal stem cells [72].

Interestingly, researchers found that matrix extracellular phosphoglycoprotein (MEPE, Dentonin, or AC-100) can augment osteoblast proliferation, resulting in the postnatal dental pulp stem cells (DPSCs) differentiating into odontoblast-like cells and dentin-pulp-like regeneration [73, 74].

Fibronectin (FN)-derived peptides like Pro-His-Ser-ArgAsn (PHSRN) can promote osteoblast adhesion, migration, and mineralization [75]. A fibrin-binding synthetic oligopeptide was derived from FN which managed to enhance bone formation in the rabbit calvarial defect model. Furthermore, Martino et al. [76] engineered multifunctional FN III9-10/ 12-14 including (i) a factor XIIIa substrate fibrin-binding sequence, (ii) the 9th to 10th type III FN repeat (FN III9-10) comprising the major integrin-binding domain, and (iii) the 12th to 14th type III FN repeat (FN III12-14), capable of binding growth factors such as vascular endothelial growth factor-A165 (VEGF-A165), platelet-derived growth factorBB (PDGF-BB), and BMP-2. The multifunctional FN III910/12-14 significantly enhanced the regenerative effects of the growth factors in a critical-size bone defect model.

Since cell integrin-binding is not the only mechanism in osteoblast adhesion, Phe-His-Arg-Arg-Ile-Lys-Ala (FHRRIKA), Lys-Arg-Ser-Arg (KRSR), and fibroblast 
growth factor-2 (FGF-2) are recognized as heparin-binding domains in bone sialoprotein and other ECM proteins. These sequences can induce osteoblast adhesion, spreading, and bone mineralization [77, 78]. Lee et al. [79] prepared potential heparin-binding domains of FGF-2, 105-111 (F105, YKRSRYT), and 119-135 (F119, KRTGQYKLGSKTGPGQK) and immobilized them on cell culture plates. According to their results, these peptides can induce osteoblast mineralization and promote osteoblast differentiation.

\section{Bone morphogenetic protein-derived peptides}

Bone morphogenetic proteins (BMPs) are a group of growth factors capable of inducing the prompt formation of hard tissues [80]. Osteoinductive functional peptides are generally derived from BMP-2, BMP-7, and BMP-9 that can interact with the target cells through heterotetramers of serine/ threonine kinase to activate the Smad intracellular pathway. The Smad proteins are a family of intracellular co-modulators with a critical role in the transforming growth factor- $\beta$ (TGF- $\beta$ ) superfamily intracellular cascade [81]. BMP-2-derived peptides (such as P17, P20, and P24) are the key factors in inducing bone tissue regeneration and can enhance bone-repair response and induce osteogenic differentiation of BMSCs or hMSCs [81]. These peptides can regulate voltage-gated Ca2 $\beta$ channels and induce ALP activity as well as enhancing bone formation. Feng et al. [82] designed a chitosan/nanometer HAp/collagen composite (chitosan/nHAC); then, they introduced BMP-7 mimetic peptide and loaded it into the composite by vacuum adsorption. Compared to the unloaded composite, more effective bone regeneration was observed in the composite loaded with $1 \mathrm{mg}$ BMP-7 mimetic peptide.

\section{Other peptides}

Numerous peptides have been developed based on ECM and BMP, which can induce hard regeneration. Apart from these peptides, other peptides found to improve bone healing including parathyroid hormone (PTH1-34), calcitonin generelated peptide (CGRP), osteogenic growth peptide (OGP), thrombin peptide 508 (TP508), NEMO-binding domain (NBD), and cell-penetrating peptides (CPPs).

The peptide derived from a parathyroid hormone (PTH134 ) is one of the first FDA-approved synthesized peptides for the prevention and treatment of osteoporosis [83]. PTH1-34 upregulates osteoblast proliferation and differentiation as well as significantly enhancing bone mineral content and angiogenesis [84]. Therefore, this peptide is one of the most successful sequences, especially for fracture treatment. Calcitonin gene-related peptide (CGRP) is derived from two separate genes: $\alpha$ and $\beta$. Due to its valuable effects on bone regeneration, this peptide has been extensively studied. It is mainly found in bone marrow and in the metaphyses and periostea [85]. According to recent reports, CGRP not only stimulates osteoblast proliferation and new bone formation (especially in the alveolar bone), but it can also enhance the production of growth factors, such as BMP-2 and IGF-1 [86, 87]. Moreover, in vitro studies have revealed the important role of CGRP in reducing inflammation and apoptosis [88]. Osteogenic growth peptide (OGP) contains 14 amino acids and is highly conserved as an $\mathrm{H} 4$ histone-related peptide naturally found in human serum. Following its dissociation from $\alpha 2$-macroglobulin, the peptide activates an intracellular Gi-protein-MAP kinase signaling pathway [89]. OGP also stimulates transforming growth factor $\beta 1, \beta 2, \beta 3$ (TGF$\beta 1, \beta 2, \beta 3$ ), insulin-like growth factor 1 (IGF-I), fibroblast growth factor2 (FGF-2), and aggrecan in vivo. Experimental fracture healing models have revealed that OGP can accelerate the bone healing response [90].

Thrombin peptide 508 (TP508), also known as Chrysalin, is a 23-amino-acid synthetic peptide representing the non-proteolytic receptor-binding domain of human thrombin without the undesirable blood-clotting effects [91]. TP508 promotes fracture healing, proliferation, osteogenic differentiation, and increased chemotaxis in human osteoblasts [92]. Moreover, it regulates VEGF-stimulated angiogenesis and attenuates the effects of chronic hypoxia [93].

Kappa-B kinase (IKK) is a nuclear factor inhibitor consisting of two catalytic subunits, IKK-1 and IKK-2, with a non-catalytic regulatory subunit NF-kB essential modulator (NEMO or IKK-c) [94]. NEMO-binding domain (NBD) is an interacting binding site with 6 amino acids, where IKK subunits interact with NEMO. Thus, the NBD peptide induces osteoblast differentiation and inhibits bone resorption [95].

Cell-penetrating peptides (CPPs) are promising peptides capable of transporting various cargos such as nanoparticles, oligonucleotides, and proteins into the cytoplasm through cell membranes. Thus, CPPs can act as transcriptional factors to transfer hard tissue repair factors such as BMP-2 into MSCs to enhance bone formation [96]. Lee et al. [97] designed six bioactive synthetic peptides from a calcium phospholipid-binding protein, copine 7 (CPNE7), to induce hard tissue regeneration. Quantitative real-time PCR indicated high expression of osteogenic markers like ALP and CDP4 and showed the highest cell penetration level as well as osteogenic efficiency in dental pulp stem cells (DPSCs). Also, the mixture of CDP4 with injectable collagen gel enhanced bone formation with recovery in the mouse calvarial defect model, in comparison with full-length CPNE7 and BMP-2. Altogether, it seems that a combination of cell-binding peptides with low doses of BMPs or with other peptides can enhance the effectiveness of bioactive peptide hydrogels in tissue engineering [98]. To provide broad accessibility to the topic, each group is briefly summarized in Table 1 . 


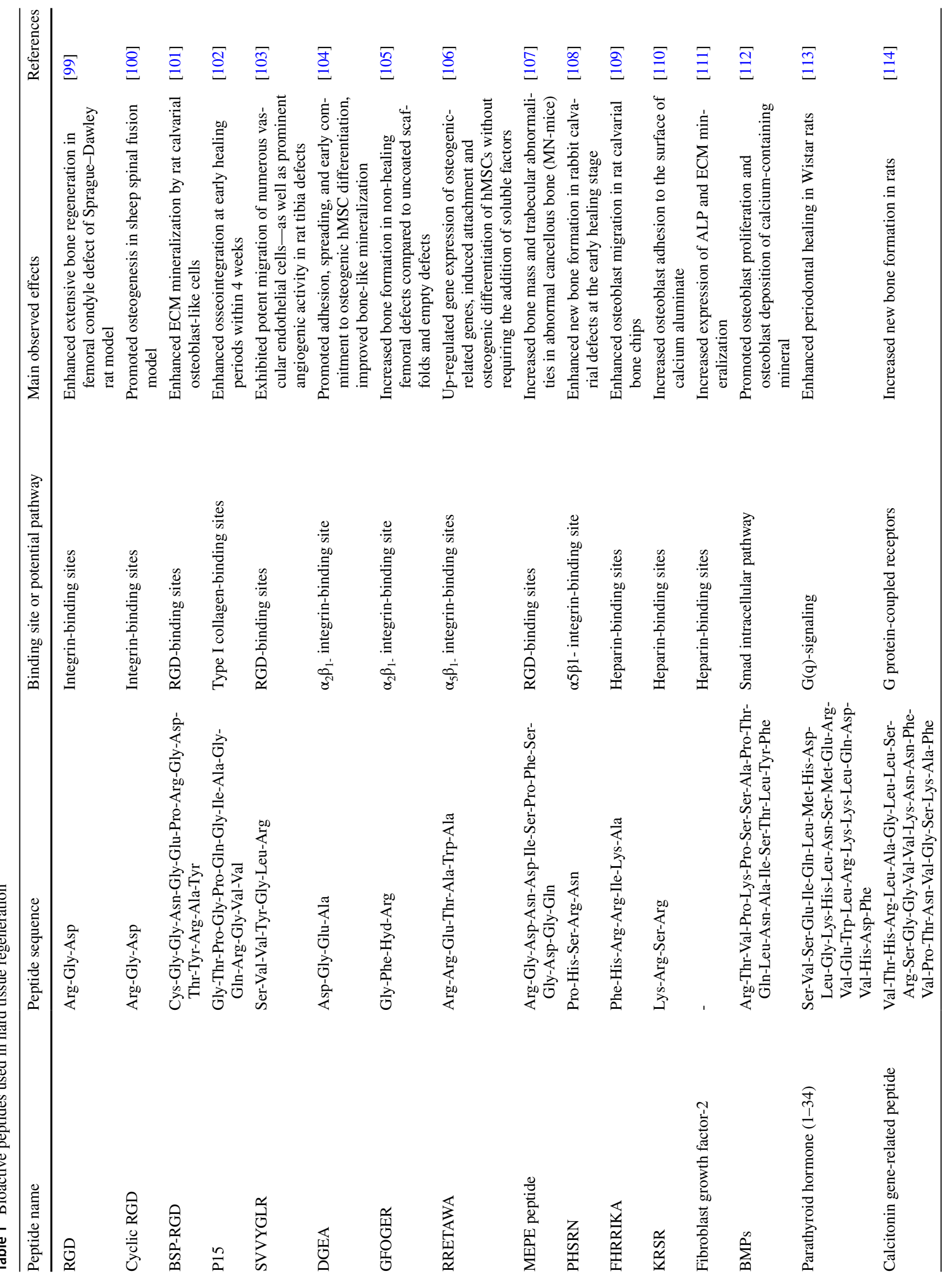




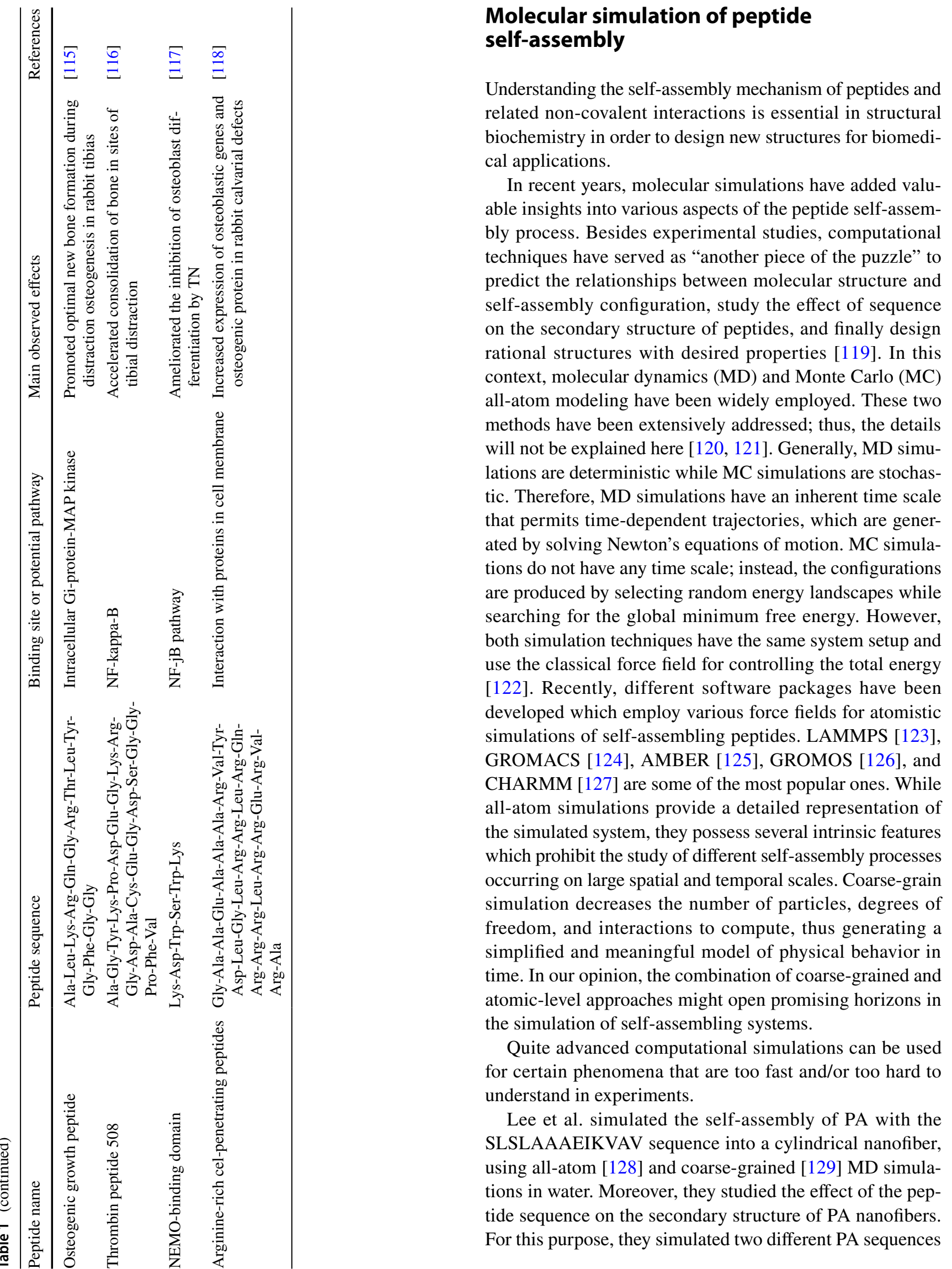


with different numbers of valines. Their results indicated that the PA containing more valine residues showed more population of $\beta$-sheet structure and non-covalent interactions [130]. Fu et al. [131] also investigated the role of hydrophobic interactions in the self-assembly of PA molecules, using a novel coarse-grained MD simulation. They showed that with the increase of hydrophobic interaction, cylindrical nanostructures containing either $\beta$-sheets or random coils will be formed.

\section{Application of self-assembled peptide hydrogels in bone tissue regenerations}

The past few decades have witnessed a noticeable increase in the number of studies on the use of peptides in bone tissue engineering. A wide range of designed self-assembling peptides can be employed as scaffolds for culturing bone cells and bone regeneration [55]. Quan et al. developed a 3D bioactive scaffold from self-assembled oligopeptides of D9 KIPKASSVPTELSAIS RGDS (DSR) and D9 KIPKASS(p) V PTELSAIS RGDS (DSpR), and included the bone morphogenetic protein-2 biomimetic peptide (BMPMP) as a potent osteoinductive cytokine, polyaspartic acid (D9) as the organic template, and a calcium chelating agent and RGDS as cell adhesion factors to synergistically promote bone regeneration. These oligopeptides were synthesized by a solid-phase method using Fmoc/tBu. Cell culture studies indicated that the RGDS and BMPMP not only promoted osteogenic gene expression (OPN, RUNX2, OCN, ALP, and BMP-2) but also accelerated the proliferation and differentiation of rat marrow mesenchymal stem cells (rMSC) toward the osteoblast. Moreover, results in a rat cranial bone defects model confirmed that rMSCs-loaded hydrogel accelerated bone formation via synergistic action of phosphorylation and BMPBP on the differentiation of rMSCs (Fig. 4) [132].

PA can be utilized as an ideal template for the deposition of HAp crystals [133]. For instance, Eren et al. designed a mineralized PA nanofiber with a Lauryl-Val-Val-Ala-GlyGlu-Glu-Glu (E3-PA) sequence using the Fmoc solid-phase method to induce osteogenic differentiation. They found that PA with three glutamic acids is highly efficient for the formation of HAp nanocrystals and nucleation of calcium phosphate. Gene expression analysis and ALP activity assay showed that the presence of HAp in peptide nanofibers can enhance the osteogenic differentiation of cells (Saos-2 cells) and improve the bioactivity of scaffold systems compared to non-mineralized peptide-based scaffold cells [134]. It is known that the use of self-assembling peptides with acidic groups at low $\mathrm{pH}$ is harmful to cells and host tissues [135]. Tsukamoto et al. [136] applied a SPG-178 peptide with a Arg-Leu-Asp-Leu-Arg-Leu-Ala-Leu-Arg-Leu-Asp-Leu-Arg sequence to create a stable self-assembling peptide hydrogel (SPG-178-hydrogel) at natural $\mathrm{pH}$. This particular peptide has a high isoelectric point $(\mathrm{pI}=11.5)$ for bone reconstruction in rat calvarial defect models. Previous studies have reported that dental pulp stem cells (DPSCs) had high proliferation potency in their differentiation into neuronal cells, adipocytes, odontoblasts, and osteoblasts [137, 138]. This particular study by Tsukamoto et al. revealed that SPG178 hydrogel has osteoconductive activity and is highly biocompatible. Moreover, the osteogenic differentiation of DPSCs into osteoblast-like cells in three-dimensional cell culture using SPG-178-hydrogel was confirmed by significantly increased gene expression levels of osteocalcin, collagen type I, and osteopontin. In another study, He et al. reported synthetic L-RADA16 and D- RADA16 peptide nanofibers that produced stable $\beta$-sheet secondary structures and peptide hydrogel scaffold, respectively. These peptides were synthesized via the solid-phase peptide synthesis method. The authors reported that both Dand L-RADA 16 hydrogels could promote fracture healing in condyle defects of Sprague-Dawley rats. The results of micro-computed tomography (micro-CT) analysis revealed that the D-RADA16 peptide hydrogel, in comparison with the L-RADA16, played a crucial role in bone grafts and controlled release of basic fibroblast growth factors (bFGF). The controlled release of bFGF as a signaling molecule resulted in extensive fracture healing in Sprague-Dawley rats. [139] Similarly, Zhou et al. [140] developed D-RADA16 hydrogelcontaining TGF- $\beta 1$ resulted in a controlled release of growth factor to stimulate and promote the osteogenesis via increasing the proliferation of BMSCs. In another study, Castillo Diaz et al. [141] explored the capability of octapeptide hydrogel with the sequence of Phe-Glu-Phe-Glu-Phe-LysPhe-Lys to host hMSC in 3D culture medium and induce osteogenic differentiation of hMSCs. Their assays showed that the ionic-complementary peptide hydrogel performed as a 3D scaffold for proliferation and differentiation of hMSCs into osteoblasts cells and enhanced the mineralization under osteogenic stimuli. Moreover, these differentiated cells could produce key bone proteins (i.e., ALP, OCN, and Col-1) involved in bone formation. Previous studies have shown that utilizing a glycosaminoglycan [142] mimetic system with osteoinductive features results in osteogenic differentiation of cells and promotes bone formation [143]. Kocabey et al. [144] designed a GAG mimetic peptide nanofiber capable of interacting with BMP-2 and providing a favorable microenvironment for bone reconstruction and mineralization. Cell culture examinations indicated enhanced calcium deposition and ALP activity, which are the early indicators of bone maturation. A summary of the examples mentioned above is presented in Table 2. 

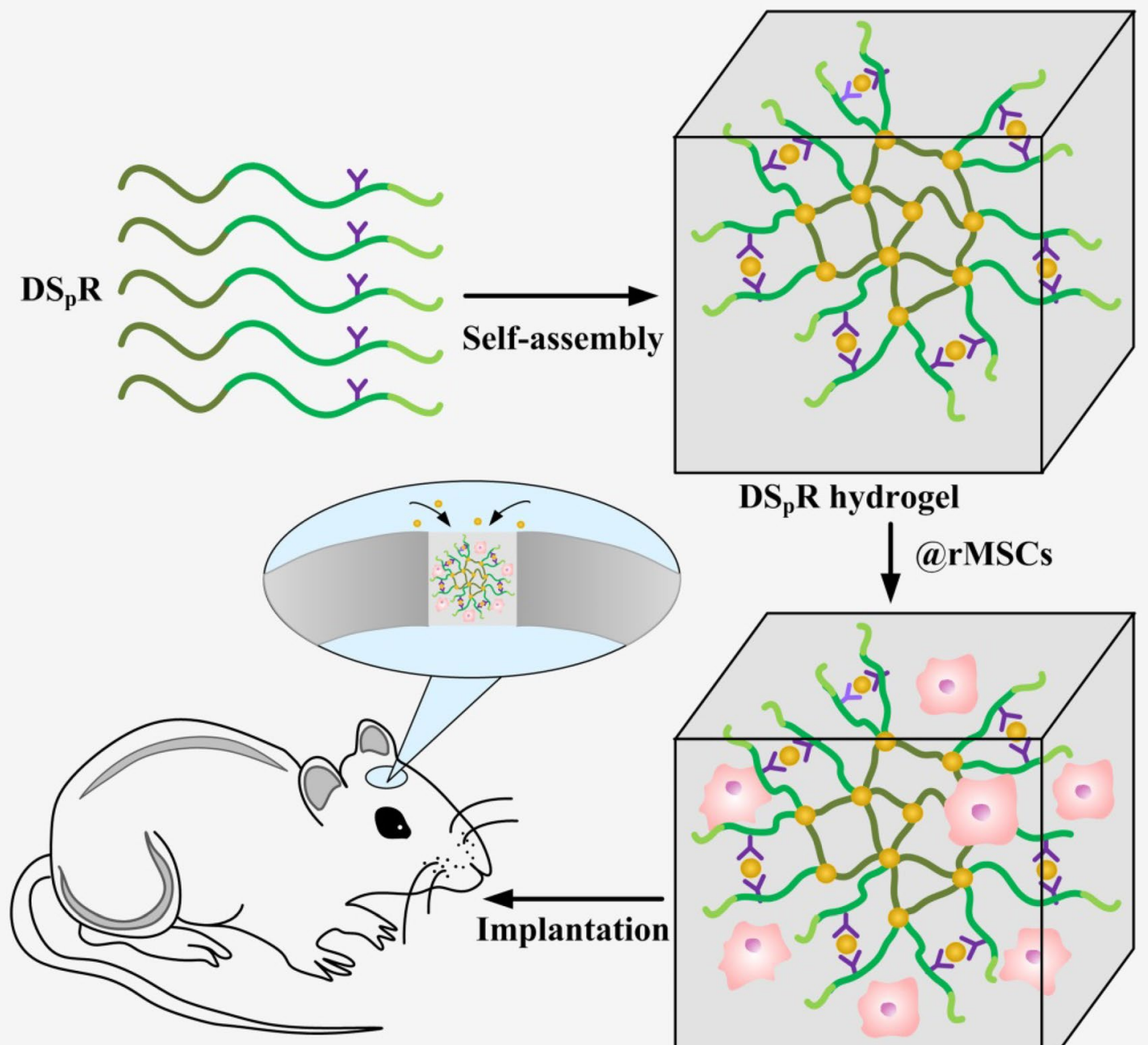

DS $_{\mathrm{p}} \mathrm{R}$ hydrogel

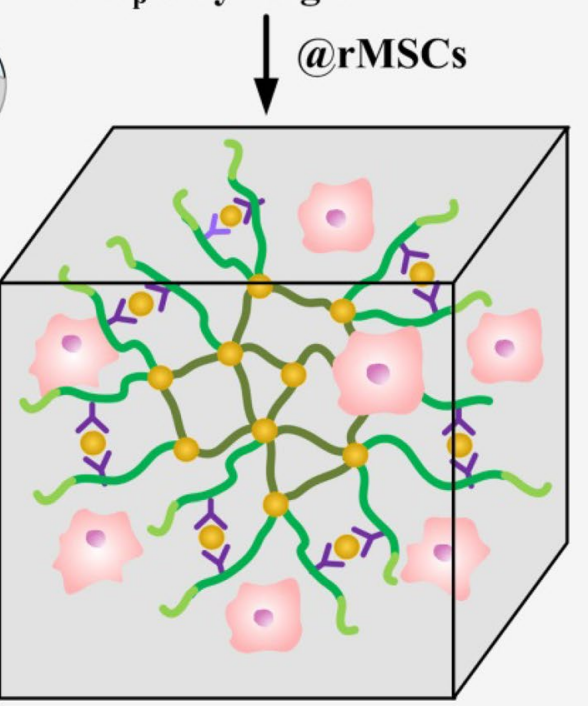

$\mathrm{DS}_{\mathrm{p}} \mathrm{R}$ @rMSCs

Ployaspartic acid

BMP-2

RGDS Y Phosphate group

$\mathrm{Ca}^{2+}$

Fig. 4 Illustration of 3D-bioactive gel scaffold from self-assembled DSpR oligopeptide composed of polyaspartic acid, RGDS, and BMP-2 with phosphate groups and $\mathrm{Ca}^{2+}$ ions for the repair of rat cranial bone defects [132] (Reproduced with permission from Ref. [132] @) 2018 Elsevier)

\section{Application of self-assembled peptide hydrogels in dental tissue regeneration}

Caries and dental trauma are considered the main causes of dental loss. Generally, microbial activity leads to enamel destruction and eventually to tooth loss [145]. Enamel is a type of dental support tissue and is considered to be the stiffest mineralized tissue in the body. It is composed of thousands of anisotropically aligned hydroxyapatite crystals [146]. Enamel is formed in a complex mineralization process and does not have any innate regeneration capability to defend against the acidic media which are produced by caries activity. Currently, major efforts are concentrated on the prevention of dental caries, including effective remineralization process enhancement in initial dental rot and prevention of microbial film formation [147]. Among selfassembling structures, self-assembled peptide hydrogels are comparatively the most desirable candidates for the treatment of caries and tooth regeneration [148]. Alkilzy et al. [148] utilized SAPs for caries management. To do so, they designed a P11-4 peptide (Ac-Gln-Gln-Arg-PheGlu-Trp-Glu-Phe-Glu-Gln-Gln-NH2), chosen for its high affinity to hydroxyapatite HAp and capability to nucleate hydroxyapatite. In particular, the peptide formed a 


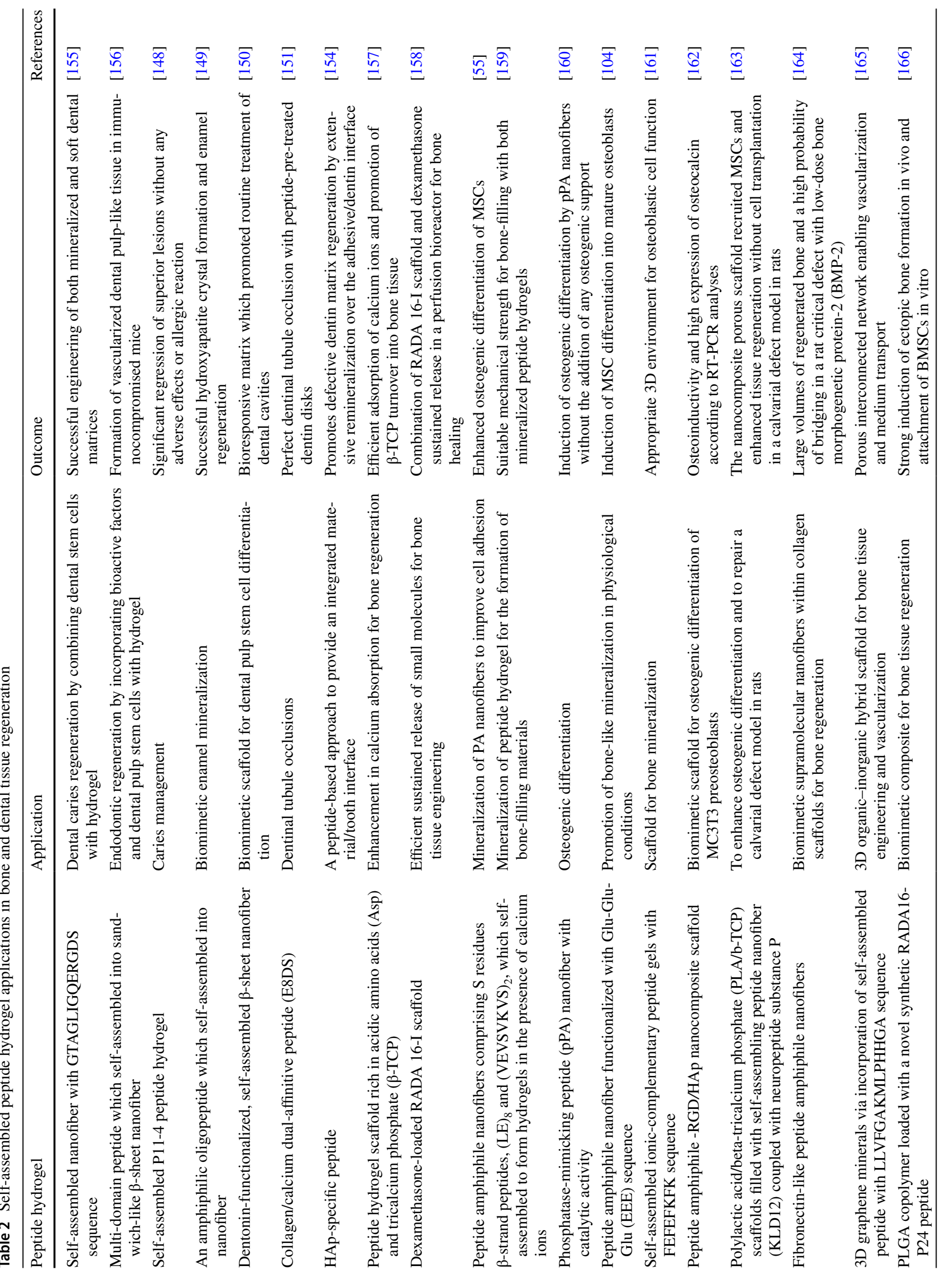


3D structure with the calcium-binding sites, which could serve as the HAp nucleation point. Moreover, P11-4 selfassembled in an acidic $\mathrm{pH}$ caries lesion environment and made a suitable scaffold for enamel remineralization. Clinical assessments after 3 and 6 months showed a significant regression of superior lesion without any adverse effects or allergic reaction. Li et al. utilized an amphiphile oligopeptide-containing amelogenin hydrophilic functional domain (Thr-Lys-Arg-Glu-Glu-Val-Asp) and a stearic acid derivative $(\mathrm{C} 18 \mathrm{H} 35 \mathrm{COOH})$ as a hydrophobic block for biomimetic enamel mineralization. The oligopeptide self-assembly occurred in the presence of calcium ions, and nanofibers were formed. According to the results, amorphous calcium phosphate was nucleated and grown along the nanofibers, while it was repeatedly exposed to calciumand phosphate-ion-containing solutions. Furthermore, its incubation with acid-etched human enamel sections under metastable calcium phosphate solution at $37{ }^{\circ} \mathrm{C}$ led to the formation of HAp crystals and finally to enamel regeneration [149]. In another study, Nguyen et al. designed an injectable and biodegradable self-assembled peptide hydrogel as a biomimetic scaffold for dental pulp stem cell differentiation. To achieve this, dentonin was attached to a self-assembled peptide framework containing a sequence similar to a formerly defined self-assembling peptide. The designed peptide self-assembled to form $\beta$-sheet nanofibers (Fig. 5). Dentonin is a bioactive section of the phosphoglycoprotein extracellular matrix that promotes the proliferation of postnatal dental pulp stem cells. The self-assembled hydrogel displayed a thixotropic nature and its cytocompatibility with dental pulp stem cells and fibroblasts was confirmed. As the result showed, this system served as an ideal engineered bioresponsive matrix for promoting routine dental cavities treatment, although in vivo viability must be evaluated in the future [150].

Wang et al. [151] designed a collagen/calcium dual-affinitive peptide (E8DS) as a biomaterial for dentinal tubule occlusions. The E8DS peptide (EEEEEEEEDSpESpSpEEDR) was synthesized with the solid-phase peptide synthesis method; the developed peptide effectively enhanced the binding of nano-hydroxyapatite to dentin. The results showed that almost $43.7 \%$ of initial dentin-immobilized peptide remained after washing with distilled water (rate of $1 \mathrm{~mL} / \mathrm{min}$ ) for 4 weeks, reflecting its strong affinity to the dentin collagen matrix. Also, peptide-pretreated dentin disks exhibited perfect dentinal tubule occlusion in comparison with both commercial desensitizer and nano-hydroxyapatite.

Generally, resin-based composites have been the most prominent material for dental restoration, but their short lifetime has limited their clinical usage [152]. Indeed, they undergo in vivo degradation due to recurrent caries at the tooth-composite interface. Since viscous materials cannot directly attach to the tooth, an adhesive with low viscosity 


\section{KSLSLSLSLSLSLK-G-TDLQERGDNDISPFGDGQPFKD}

\section{Peptide framework Dentonin}

A

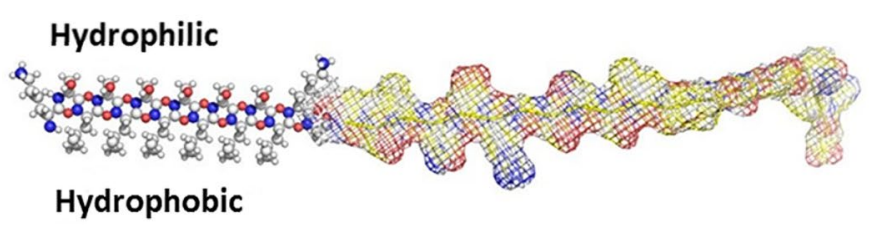

B
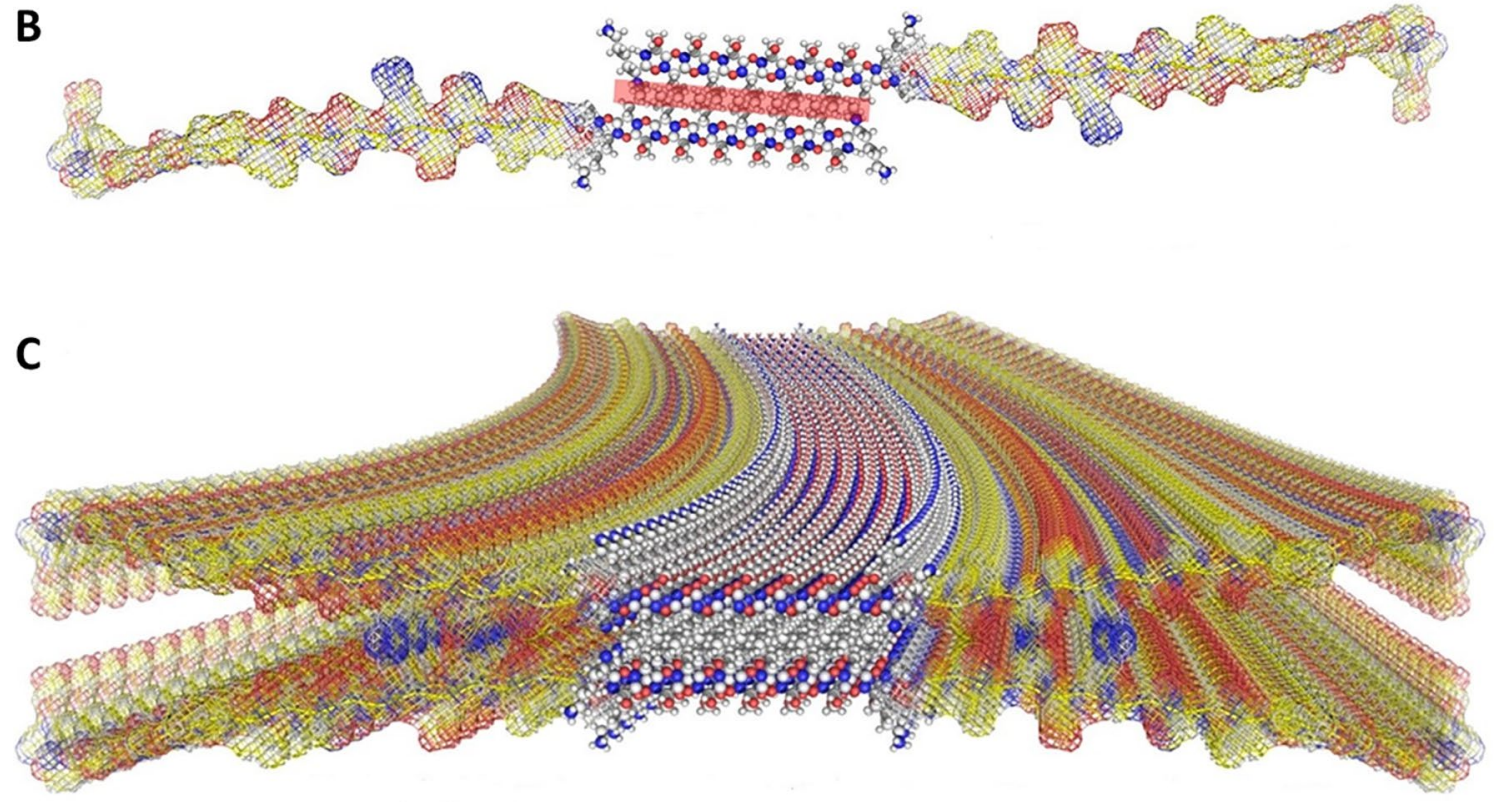

Fig. 5 Schematic illustration of the designed peptide's sequences and how it self-assembles to form $\beta$-sheet-based nanofiber hydrogels in water (a-c) [150] (Reproduced with permission from Ref. [150] @ 2018 American Chemical Society)

is used to form a connection between the composite and tooth. The connection between the adhesive and dentin will be degraded due to bacterial, salivary, and endogenous enzymes [153]. Using peptide-mediated remineralization of dentin provides interfacial integration and is a promising solution. Ye et al. [154] investigated the inherent peptidebased approach to providing an integrated material/tooth interface. For this purpose, the defective dentin matrix was re-mineralized by an engineered HAp-specific peptide. The peptide was self-anchored to the adhesive/dentin interface and promoted defective dentin matrix regeneration by extensive remineralization over the entire adhesive/dentin interface. Therefore, this approach is a promising platform for overcoming the drawbacks of conventional dental composites. The role of self-assembled peptide hydrogels in dental tissue regeneration is summarized in Table 2.

Altogether, self-assembled peptide hydrogels play a pivotal role in dental tissue regeneration by promoting HAp nucleation, self-anchoring to the adhesive/dentin interface, and providing desirable cytocompatibility with dental pulp stem cells and fibroblasts.

\section{Conclusions and future outlook}

Annually, hard tissue regeneration imposes vast public healthcare costs which will significantly increase associety ages. Accordingly, the development of appropriate biomaterials for hard tissue repair and regeneration is an important task. Peptides are a new generation of promising biomaterials with highly versatile structural building blocks, which can construct supramolecular architectures such as fibers, sheets, tubes, spheres, and tapes. The self-assembled hydrogels are novel nanostructures, which can be formed through molecular self-assembly interactions, including hydrogen bonding, electrostatic interactions, $\pi-\pi$ stacking, and hydrophobic interactions. They exhibit excellent biocompatibility, tunable mechanical stability, injectability, trigger capability, 
lack of immunogenic reaction, and ability to load cells and active pharmaceutical agents (e.g., proteins, nucleic acids, and small molecule drugs) [168]. Up to now, the prediction of the structures of SAPs based on their sequence and other physiochemical properties has remained controversial. Thus, further studies are required for deeper understanding of the relationship between the morphology of SAPs and their physicochemical properties (e.g., size, charge, sequence) in rational peptide design. Molecular simulation provides valuable information about the formation of self-assembled peptide hydrogels. Moreover, the presence of charged amino acids in a peptide sequence stimulates its interactions with calcium phosphate ions, making it possible to use hydrogels for HAp nucleation. One of the important requirements of regenerative hydrogels is their ability to enhance the proliferation and differentiation of cells. Therefore, surface modification of peptides with specific binding sequences or growth factors can ensure proper cell attachment. Generally, biofunctionalized peptide scaffolds have the ability to promote osteogenic differentiation and osteointegration, especially in bone tissue engineering. It seems that a combination of two or three peptide groups can increment the effectiveness of bioactive peptide hydrogels in tissue engineering.

Successful hard tissue regeneration requires coordinated interaction among cells, growth factors, and hydrogel scaffold. Although biomimetic SAP hydrogels show promising features for hard tissue regeneration, there are still several shortcomings that should be resolved. The relationship between the morphology, physicochemical properties, and biological activity of SAP hydrogels should be elucidated in more detail. To improve control over the structure of synthesized SAPs, we propose modulation of conventional fabrication parameters or the use of new methods such as template-assisted synthesis. The stability of functionalized peptide nanostructures also needs to be considered. For instance, alkaline $\mathrm{pH}$ can improve aromatic peptide stability in liquid solution, but at the same time can impair the chemical stability of L-glutamine-containing peptides. High mechanical and structural support is required for regeneration of large bone defects and cannot be easily afforded with SAP hydrogels alone. In addition, rapid SAP hydrogel degradation prior to the generation of new ECM can disrupt the mechanical stability of hydrogels. These pitfalls can be overcome by introducing composite materials such as metals, carbon nanomaterials, or synthetic polymers [169]. The impact of SAP sequences on the immune system is not well known and can vary from non-immunogenic to selfadjuvating in each design. Therefore, future works should be directed toward biocompatibility and immunogenicity of SAP hydrogels.

Antimicrobial peptides (AMPs) and piezoelectric peptides are promising candidates for implantable devices for use in human health monitoring and hard tissue engineering.
Generally, emergence of infection in hard tissue regeneration is a clinically relevant challenge. Development of scaffolds with dual function for promoting bone/dental tissue growth and preventing bacterial infection is a critical point for clinical application. AMPs have been attracting much attention due to their excellent antimicrobial efficiency and lack of association with escalated antimicrobial resistance. Efforts have also been made to develop electrically active piezoelectric peptides that demonstrate potential for bone engineering by providing electrical stimulation to cells. Piezoelectric peptides can enhance tissue formation by providing an electrically active microenvironment without external power sources for electrical stimulation.

SAP manufacturing methods have evolved over the last two decades, going from fixed, dedicated, and investmentheavy production lines to conventional but modular assemblies, and to low-cost, single-batch micro-production setups. However, there are still some challenges to be overcome in detection and removal of peptide impurities in large-scale production before clinical translation. The other issue that has often been overlooked in the literature is the sterilization process for peptide hydrogels. This is required to ensure the sterility of SAP hydrogels; however, the sterilization method should conserve the assembly and functionality of the peptide hydrogels. Conventional sterilization methods such as UV irradiation, heat, and high pressure can deteriorate the function of the bioactive macromolecules. In addition, the recently emerged sterilization methods such as freeze-drying and supercritical carbon dioxide may affect porosity, morphology, and bioactivity of peptide scaffolds.

Compounds destined for medical purposes are subject to strict regulatory and quality control requirements that drive their cost up and narrow the scope for early application. For human use, GMP (good manufacturing practices) must be followed in high-purity peptide production and the processes must be compliant with the relevant requirements of regulatory agencies. Functional and structural reproducibility of a SAP hydrogel is critical for scaffold materials to pass through various regulatory requirements, particularly for complex hydrogel systems containing biological materials. Quality control and precise quantification of these biological materials are vital for batch-to-batch consistency of SAP hydrogels. Large-scale bio-fabrication of cell-encapsulated SAP hydrogels is especially challenging. Therefore, cellfree peptide hydrogels might be more suitable for large-scale production, while cell-encapsulated scaffolds might be more appropriate for the development of personalized medicine.

Despite these remaining challenges, we envision that SAPs will have vital therapeutic applications in hard tissue regeneration. Numerous studies have addressed tissue regeneration and more clinical trials are underway. Therefore, these SAPs will probably be used as a realistic therapeutic choice for human medical care. 
Acknowledgements The authors would like to thank Prof. Alimohammad Tamaddon, Founder and Executive Director of the "Center for Nanotechnology in Drug Delivery, Shiraz University of Medical Sciences," for his kind cooperation.

Author contributions HN, MJ, GF, SSA, NA, SB, and RR all contributed to writing original draft and editing the final version of the review manuscript.

\section{Declarations}

Conflict of interest The authors declare that there is no conflict of interest.

Ethical approval This article does not contain any studies with human or animal subjects performed by any of the authors.

\section{References}

1. Liu Q, Limthongkul W, Sidhu G et al (2012) Covalent attachment of P15 peptide to titanium surfaces enhances cell attachment, spreading, and osteogenic gene expression. J Orthop Res 30(10):1626-1633. https://doi.org/10.1002/jor.22116

2. Zhang K, Wang S, Zhou C et al (2018) Advanced smart biomaterials and constructs for hard tissue engineering and regeneration. Bone Res 6(1):31. https://doi.org/10.1038/s41413-018-0032-9

3. He B, Zhao J, Ou Y et al (2018) Biofunctionalized peptide nanofiber-based composite scaffolds for bone regeneration. Mater Sci Eng C Mater Biol Appl 90:728-738. https://doi.org/ 10.1016/j.msec.2018.04.063

4. Najafi H, Abolmaali SS, Owrangi B et al (2015) Serum resistant and enhanced transfection of plasmid DNA by PEG-stabilized polyplex nanoparticles of L-histidine substituted polyethyleneimine. Macromol Res 23(7):618-627. https://doi.org/10.1007/ s13233-015-3074-5

5. Rafiemanzelat F, Jafari M, Emtiazi G (2015) Study of biological degradation of new poly (ether-urethane-urea) s containing cyclopeptide moiety and PEG by Bacillus amyloliquefaciens isolated from soil. Appl Biochem Biotechnol 177(4):842-860. https://doi.org/10.1007/s12010-015-1782-0

6. Jafari M, Abolmaali SS, Najafi H et al (2020) Hyperbranched polyglycerol nanostructures for anti-biofouling, multifunctional drug delivery, bioimaging and theranostic applications. Int J Pharm 576:118959. https://doi.org/10.1016/j.ijpharm.2019.118959

7. Wen Y, Roudebush SL, Buckholtz GA et al (2014) Coassembly of amphiphilic peptide EAK16-II with histidinylated analogues and implications for functionalization of beta-sheet fibrils in vivo. Biomaterials 35(19):5196-5205. https://doi.org/10.1016/j.bioma terials.2014.03.009

8. Abolmaali SS, Tamaddon A, Najafi $\mathrm{H}$ et al (2014) Effect of 1-Histidine substitution on Sol-Gel of transition metal coordinated poly ethyleneimine: synthesis and biochemical characterization. J Inorg Organomet Polym Mater 24(6):977-987. https://doi.org/ 10.1007/s10904-014-0067-3

9. Hosseinkhani H, Hong PD, Yu DS (2013) Self-assembled proteins and peptides for regenerative medicine. Chem Rev 113(7):4837-4861. https://doi.org/10.1021/cr300131h

10. Han TH, Oh JK, Lee GJ et al (2010) Hierarchical assembly of diphenylalanine into dendritic nanoarchitectures. Colloids Surf B 79(2):440-445. https://doi.org/10.1016/j.colsurfb.2010.05.003

11. Chen J, Zou X (2019) Self-assemble peptide biomaterials and their biomedical applications. Bioact Mater 4:120-131. https:// doi.org/10.1016/j.bioactmat.2019.01.002
12. Sun L, Fan Z, Wang Y et al (2015) Tunable synthesis of selfassembled cyclic peptide nanotubes and nanoparticles. Soft Matter 11(19):3822-3832. https://doi.org/10.1039/c5sm00533g

13. Najafi H, Jafari M, Abolmaali S (2019) Recent approaches in the treatment of skin ageing by synthetic bioactive peptides. Sadra Medical Journal 7(3):317-334. https://doi.org/10.30476/SMSJ. 2019.81724.1000

14. Pérez CMR, Stephanopoulos N, Sur S et al (2015) The powerful functions of peptide-based bioactive matrices for regenerative medicine. Ann Biomed Eng 43(3):501-514. https://doi.org/10. 1007/s10439-014-1166-6

15. Yu Z, Cai Z, Chen Q et al (2016) Engineering beta-sheet peptide assemblies for biomedical applications. Biomater Sci 4(3):365374. https://doi.org/10.1039/c5bm00472a

16. Chan K, Zhuo S, Ni M (2013) Natural and synthetic peptidebased biomaterials for bone tissue engineering. OA Tissue Eng 1(1):6. https://doi.org/10.13172/2052-9643-1-1-787

17. Firth A, Aggeli A, Burke JL et al (2006) Biomimetic self-assembling peptides as injectable scaffolds for hard tissue engineering. Nanomedicine 1(2):189-199. https://doi.org/10.2217/17435 889.1.2.189

18. Koutsopoulos S (2016) Self-assembling peptide nanofiber hydrogels in tissue engineering and regenerative medicine: progress, design guidelines, and applications. J Biomed Mater Res A 104(4):1002-1016. https://doi.org/10.1002/jbm.a. 35638

19. Stupp SI (2005) Biomaterials for regenerative medicine. MRS Bull 30(7):546-553. https://doi.org/10.1557/mrs2005.148

20. Papapostolou D, Smith AM, Atkins ED et al (2007) Engineering nanoscale order into a designed protein fiber. Proc Natl Acad Sci 104(26):10853-10858. https://doi.org/10.1073/pnas.0700801104

21. Mehrban N, Zhu B, Tamagnini F et al (2015) Functionalized alpha-helical peptide hydrogels for neural tissue engineering. ACS Biomater Sci Eng 1(6):431-439. https://doi.org/10.1021/ acsbiomaterials.5b00051

22. McDaniel JR, Callahan DJ, Chilkoti A (2010) Drug delivery to solid tumors by elastin-like polypeptides. Adv Drug Deliv Rev 62(15):1456-1467. https://doi.org/10.1016/j.addr.2010.05.004

23. MacEwan SR, Chilkoti A (2014) Applications of elastin-like polypeptides in drug delivery. J Control Release 190:314-330. https://doi.org/10.1016/j.jconrel.2014.06.028

24. Nasrolahi Shirazi A, Tiwari RK, Oh D et al (2013) Efficient delivery of cell impermeable phosphopeptides by a cyclic peptide amphiphile containing tryptophan and arginine. Mol Pharm 10(5):2008-2020. https://doi.org/10.1021/mp400046u

25. Liu H, Chen J, Shen Q et al (2010) Molecular insights on the cyclic peptide nanotube-mediated transportation of antitumor drug 5-fluorouracil. Mol Pharm 7(6):1985-1994. https://doi.org/ $10.1021 / \mathrm{mp} 100274 \mathrm{f}$

26. Branco MC, Schneider JP (2009) Self-assembling materials for therapeutic delivery. Acta Biomater 5(3):817-831. https://doi. org/10.1016/j.actbio.2008.09.018

27. Zhang S (2003) Fabrication of novel biomaterials through molecular self-assembly. Nat Biotechnol 21(10):1171-1178. https:// doi.org/10.1038/nbt874

28. Cui H, Webber MJ, Stupp SI (2010) Self-assembly of peptide amphiphiles: from molecules to nanostructures to biomaterials. Biopolym 94(1):1-18. https://doi.org/10.1002/bip.21328

29. Jung JP, Jones JL, Cronier SA et al (2008) Modulating the mechanical properties of self-assembled peptide hydrogels via native chemical ligation. Biomaterials 29(13):2143-2151. https:// doi.org/10.1016/j.biomaterials.2008.01.008

30. Pochan DJ, Schneider JP, Kretsinger J et al (2003) Thermally reversible hydrogels via intramolecular folding and consequent self-assembly of a de novo designed peptide. J Am Chem Soc 125(39):11802-11803. https://doi.org/10.1021/ja0353154 
31. Najafi H, Tamaddon AM, Abolmaali S et al (2021) Structural, mechanical, and biological characterization of hierarchical nanofibrous Fmoc-phenylalanine-valine hydrogels for 3D culture of differentiated and mesenchymal stem cells. Soft Matter 17(1):57-67. https://doi.org/10.1039/d0sm01299h

32. Eskandari S, Guerin T, Toth I et al (2017) Recent advances in self-assembled peptides: Implications for targeted drug delivery and vaccine engineering. Adv Drug Deliv Rev 110-111:169187. https://doi.org/10.1016/j.addr.2016.06.013

33. Brea RJ, Reiriz C, Granja JR (2010) Towards functional bionanomaterials based on self-assembling cyclic peptide nanotubes. Chem Soc Rev 39(5):1448-1456. https://doi.org/10.1039/b8057 $53 \mathrm{~m}$

34. He B, Yuan X, Jiang D (2014) Molecular self-assembly guides the fabrication of peptide nanofiber scaffolds for nerve repair. RSC Adv 4(45):23610-23621. https://doi.org/10.1039/C4RA0 $1826 \mathrm{E}$

35. Luo Z, Zhang S (2012) Designer nanomaterials using chiral selfassembling peptide systems and their emerging benefit for society. Chem Soc Rev 41(13):4736-4754. https://doi.org/10.1039/ C2CS15360B

36. Hauser CA, Zhang S (2010) Designer self-assembling peptide nanofiber biological materials. Chem Soc Rev 39(8):2780-2790. https://doi.org/10.1039/b921448h

37. Mandal D, Nasrolahi Shirazi A, Parang K (2014) Self-assembly of peptides to nanostructures. Org Biomol Chem 12(22):35443561. https://doi.org/10.1039/c4ob00447g

38. Luo T, Kiick KL (2013) Collagen-like peptides and peptidepolymer conjugates in the design of assembled materials. Eur Polymer J 49(10):2998-3009. https://doi.org/10.1016/j.eurpo lymj.2013.05.013

39. Li J, Kuang Y, Gao Y et al (2013) D-amino acids boost the selectivity and confer supramolecular hydrogels of a nonsteroidal antiinflammatory drug (NSAID). J Am Chem Soc 135(2):542-545. https://doi.org/10.1021/ja310019x

40. Moore AN, Hartgerink JD (2017) Self-assembling multidomain peptide nanofibers for delivery of bioactive molecules and tissue regeneration. Acc Chem Res 50(4):714-722. https://doi.org/10. 1021/acs.accounts.6b00553

41. Li Z, Hou T, Luo F et al (2014) Bone marrow enriched graft, modified by self-assembly peptide, repairs critically-sized femur defects in goats. Int Orthop 38(11):2391-2398. https://doi.org/ 10.1007/s00264-014-2388-9

42. Nakahara H, Misawa H, Yoshida A et al (2010) Bone repair using a hybrid scaffold of self-assembling peptide PuraMatrix and polyetheretherketone cage in rats. Cell Transpl 19(6-7):791-797. https://doi.org/10.3727/096368910X508906

43. Zhang F, Shi GS, Ren LF et al (2009) Designer self-assembling peptide scaffold stimulates pre-osteoblast attachment, spreading and proliferation. J Mater Sci Mater Med 20(7):1475-1481. https://doi.org/10.1007/s10856-009-3700-x

44. Gelse K, Pöschl E, Aigner T (2003) Collagens-structure, function, and biosynthesis. Adv Drug Deliv Rev 55(12):1531-1546. https://doi.org/10.1016/j.addr.2003.08.002

45. Jin HE, Jang J, Chung J et al (2015) Biomimetic self-templated hierarchical structures of collagen-like peptide amphiphiles. Nano Lett 15(10):7138-7145. https://doi.org/10.1021/acs.nanol ett. 5 b03313

46. Pires MM, Lee J, Ernenwein D et al (2012) Controlling the morphology of metal-promoted higher ordered assemblies of collagen peptides with varied core lengths. Langmuir 28(4):19931997. https://doi.org/10.1021/la203848r

47. Persikov AV, Ramshaw JA, Brodsky B (2005) Prediction of collagen stability from amino acid sequence. J Biol Chem 280(19):19343-19349. https://doi.org/10.1074/jbc.M5016 57200
48. Krishna OD, Jha AK, Jia X et al (2011) Integrin-mediated adhesion and proliferation of human MSCs elicited by a hydroxyproline-lacking, collagen-like peptide. Biomaterials 32(27):64126424. https://doi.org/10.1016/j.biomaterials.2011.05.034

49. Yamazaki CM, Asada S, Kitagawa K et al (2008) Artificial collagen gels via self-assembly of de novo designed peptides. Biopolymers 90(6):816-823. https://doi.org/10.1002/bip.21100

50. Beazoglou T, Eklund S, Heffley D et al (2007) Economic impact of regulating the use of amalgam restorations. Public Health Rep 122(5):657-663. https://doi.org/10.1177/003335490712200513

51. Chung WJ, Kwon KY, Song J et al (2011) Evolutionary screening of collagen-like peptides that nucleate hydroxyapatite crystals. Langmuir 27(12):7620-7628. https://doi.org/10.1021/la104757g

52. Koss K, Unsworth L (2016) Neural tissue engineering: bioresponsive nanoscaffolds using engineered self-assembling peptides. Acta Biomater 44:2-15. https://doi.org/10.1016/j.actbio. 2016.08.026

53. Pountos I, Panteli M, Lampropoulos A et al (2016) The role of peptides in bone healing and regeneration: a systematic review. BMC Med 14(1):103. https://doi.org/10.1186/ s12916-016-0646-y

54. Hartgerink JD, Beniash E, Stupp SI (2001) Self-assembly and mineralization of peptide-amphiphile nanofibers. Science 294(5547):1684-1688. https://doi.org/10.1126/science.1063187

55. Sargeant TD, Aparicio C, Goldberger JE et al (2012) Mineralization of peptide amphiphile nanofibers and its effect on the differentiation of human mesenchymal stem cells. Acta Biomater 8(7):2456-2465. https://doi.org/10.1016/j.actbio.2012.03.026

56. Behanna HA, Donners JJ, Gordon AC et al (2005) Coassembly of amphiphiles with opposite peptide polarities into nanofibers. JACS 127(4):1193-1200. https://doi.org/10.1021/ja044863u

57. Michel G, Tonon T, Scornet D et al (2010) The cell wall polysaccharide metabolism of the brown alga Ectocarpus siliculosus Insights into the evolution of extracellular matrix polysaccharides in Eukaryotes. New Phytol 188(1):82-97. https://doi.org/ 10.1111/j.1469-8137.2010.03374

58. Shekaran A, Garcia AJ (2011) Extracellular matrix-mimetic adhesive biomaterials for bone repair. J Biomed Mater Res A 96(1):261-272. https://doi.org/10.1002/jbm.a.32979

59. Chen Z, Wang X, Shao Y et al (2011) Synthetic osteogenic growth peptide promotes differentiation of human bone marrow mesenchymal stem cells to osteoblasts via RhoA/ROCK pathway. Mol Cell Biochem 358(1-2):221-227. https://doi.org/10.1007/ s11010-011-0938-7

60. Huang H, Zhao Y, Liu Z et al (2003) Enhanced osteoblast functions on RGD immobilized surface. J Oral Implantol 29(2):7379. https://doi.org/10.1563/1548-1336

61. Bilem I, Chevallier P, Plawinski L et al (2016) RGD and BMP-2 mimetic peptide crosstalk enhances osteogenic commitment of human bone marrow stem cells. Acta Biomater 36:132-142. https://doi.org/10.1016/j.actbio.2016.03.032

62. García A, Reyes C (2005) Bio-adhesive surfaces to promote osteoblast differentiation and bone formation. J Dent Res 84(5):407413. https://doi.org/10.1177/154405910508400502

63. Oh S, Moon KS, Lee SH (2013) Effect of RGD peptide-coated $\mathrm{TiO} 2$ nanotubes on the attachment, proliferation, and functionality of bone-related cells. J Nanomater 1:11. https://doi.org/10. $1155 / 2013 / 965864$

64. Anderson JM, Patterson JL, Vines JB et al (2011) Biphasic peptide amphiphile nanomatrix embedded with hydroxyapatite nanoparticles for stimulated osteoinductive response. ACS Nano 5(12):9463-9479. https://doi.org/10.1021/nn203247m

65. Emam HA, Behiri G, El-Alaily M et al (2015) The efficacy of a tissue-engineered xenograft in conjunction with sodium hyaluronate carrier in maxillary sinus augmentation: a clinical study. 
Int J Oral Maxillofac Surg 44(10):1287-1294. https://doi.org/10. 1016/j.ijom.2015.04.011

66. Yang XB, Bhatnagar RS, Li S et al (2004) Biomimetic collagen scaffolds for human bone cell growth and differentiation. Tissue Eng 10(7-8):1148-1159. https://doi.org/10.1089/ten.2004.10. 1148

67. Bhatnagar RS, Qian JJ, Wedrychowska A et al (1999) Design of biomimetic habitats for tissue engineering with $\mathrm{P}-15$, a synthetic peptide analogue of collagen. Tissue Eng 5(1):53-65. https://doi. org/10.1089/ten.1999.5.53

68. Egusa H, Kaneda Y, Akashi Y et al (2009) Enhanced bone regeneration via multimodal actions of synthetic peptide SVVYGLR on osteoprogenitors and osteoclasts. Biomater 30(27):46764686. https://doi.org/10.1016/j.biomaterials.2009.05.032

69. Park KM, Lee Y, Son JY et al (2012) In situ SVVYGLR peptide conjugation into injectable gelatin-poly (ethylene glycol)tyramine hydrogel via enzyme-mediated reaction for enhancement of endothelial cell activity and neo-vascularization. Bioconjug Chem 23(10):2042-2050. https://doi.org/10.1021/ bc300110b

70. Yoo SY, Kobayashi M, Lee PP et al (2011) Early osteogenic differentiation of mouse preosteoblasts induced by collagen-derived DGEA-peptide on nanofibrous phage tissue matrices. Biomacromol 12(4):987-996. https://doi.org/10.1021/bm1013475

71. Reyes CD, Petrie TA, Burns KL et al (2007) Biomolecular surface coating to enhance orthopaedic tissue healing and integration. Biomaterials 28(21):3228-3235. https://doi.org/10.1016/j. biomaterials.2007.04.003

72. Shin MK, Kim MK, Bae YS et al (2008) A novel collagen-binding peptide promotes osteogenic differentiation via $\mathrm{Ca} 2+/ \mathrm{calm}-$ odulin-dependent protein kinase II/ERK/AP-1 signaling pathway in human bone marrow-derived mesenchymal stem cells. Cell Signal 20(4):613-624. https://doi.org/10.1016/j.cellsig.2007.11. 012

73. Liu H, Li W, Gao C et al (2004) Dentonin, a fragment of MEPE, enhanced dental pulp stem cell proliferation. J Dent Res 83(6):496-499. https://doi.org/10.1177/154405910408300612

74. Hayashibara T, Hiraga T, Yi B et al (2004) A synthetic peptide fragment of human MEPE stimulates new bone formation in vitro and in vivo. J Bone Miner Res 19(3):455-462. https:// doi.org/10.1359/JBMR.0301263

75. Kim YJ, Park YJ, Lee YM et al (2012) The biological effects of fibrin-binding synthetic oligopeptides derived from fibronectin on osteoblast-like cells. J Periodontal Implant Sci 42(4):113-118. https://doi.org/10.5051/jpis.2012.42.4.113

76. Martino MM, Tortelli F, Mochizuki M et al (2011) Engineering the growth factor microenvironment with fibronectin domains to promote wound and bone tissue healing. Sci Transl Med. 3(100):100-189. https://doi.org/10.1126/scitranslmed.3002614

77. Gentile P, Ferreira AM, Callaghan JT et al (2017) Multilayer nanoscale encapsulation of biofunctional peptides to enhance bone tissue regeneration in vivo. Adv Healthc Mater 6(8):1601182. https://doi.org/10.1002/adhm.201601182

78. Gentile P, Ghione C, Tonda-Turo C et al (2015) Peptide functionalisation of nanocomposite polymer for bone tissue engineering using plasma surface polymerisation. RSC Adv 5(97):8003980047. https://doi.org/10.1039/C5RA15579G

79. Lee JY, Choo JE, Choi YS et al (2007) Characterization of the surface immobilized synthetic heparin binding domain derived from human fibroblast growth factor- 2 and its effect on osteoblast differentiation. J Biomed Mater Res A 83(4):970-979. https:// doi.org/10.1002/jbm.a.31351

80. Reddi AH, Reddi A (2009) Bone morphogenetic proteins (BMPs): from morphogens to metabologens. Cytokine Growth Factor Rev 20(5-6):341-342. https://doi.org/10.1016/j.cytogfr. 2009.10.015
81. Ma Y, Policastro GM, Li Q et al (2016) Concentration-dependent $\mathrm{h}$ MSC differentiation on orthogonal concentration gradients of GRGDS and BMP-2 peptides. Biomacromol 17(4):1486-1495. https://doi.org/10.1021/acs.biomac.6b00088

82. Feng B, Hu D, Zhang Y (2012) Accelerated bone regeneration by chitosan/nanometer hydroxyapatite/collagen composite incorporating BMP-7 mimetic peptide. J Hard Tissue Biol 21(4):481488. https://doi.org/10.2485/jhtb.21.481

83. Bodenner D, Redman C, Riggs A (2007) Teriparatide in the management of osteoporosis. Clin Interv Aging 2(4):499-507. https://doi.org/10.2147/cia.s241

84. Whitfield JF, Motley P, Willick GE (2002) Parathyroid hormone, its fragments and their analogs for the treatment of osteoporosis. Treat Endocrinol 1(3):175-190. https://doi.org/10.2165/00024 677-200201030-00005

85. Wang Y, Zhang L, Jia L et al (2016) Calcitonin gene-related peptide in aerobic exercise induces collateral circulation development in rat ischemia myocardium. Biomed Pharmacother 82:561-567. https://doi.org/10.1016/j.biopha.2016.05.040

86. Tian G, Zhang G, Tan YH (2013) Calcitonin gene-related peptide stimulates BMP-2 expression and the differentiation of human osteoblast-like cells in vitro. Acta Pharmacol Sin 34(11):14671474. https://doi.org/10.1038/aps.2013.41

87. Mrak E, Guidobono F, Moro G et al (2010) Calcitonin generelated peptide (CGRP) inhibits apoptosis in human osteoblasts by beta-catenin stabilization. J Cell Physiol 225(3):701-708. https://doi.org/10.1002/jcp.22266

88. Xu G, Jiang D (2014) The role and mechanism of exogenous calcitonin gene-related peptide on mesenchymal stem cell proliferation and osteogenetic formation. Cell Biochem Biophys 69(2):369-378. https://doi.org/10.1007/s12013-013-9809-z

89. Gabarin N, Gavish H, Muhlrad A et al (2001) Mitogenic Gi protein-MAP kinase signaling cascade in MC3T3-E1 osteogenic cells: Activation by C-terminal pentapeptide of osteogenic growth peptide [OGP (10-14)] and attenuation of activation by cAMP. J Struct Biol 81(4):594-603. https://doi.org/10.1002/jcb. 1083

90. Fei Q, Guo C, Xu X et al (2010) Osteogenic growth peptide enhances the proliferation of bone marrow mesenchymal stem cells from osteoprotegerin-deficient mice by CDK2/cyclin A. Acta Biochim Biophys Sin (Shanghai) 42(11):801-806. https:// doi.org/10.1093/abbs/gmq086

91. Li G, Cui Y, McILmurray L et al (2005) rhBMP-2, rhVEGF165, rhPTN and thrombin-related peptide, TP508 induce chemotaxis of human osteoblasts and microvascular endothelial cells. J Orthop Res 23(3):680-685. https://doi.org/10.1016/j.orthres. 2004.12.005

92. Vordemvenne T, Paletta JR, Hartensuer R et al (2011) Cooperative effects in differentiation and proliferation between PDGF$\mathrm{BB}$ and matrix derived synthetic peptides in human osteoblasts. BMC Musculoskelet Disord 12(1):263. https://doi.org/10.1186/ 1471-2474-12-263

93. Olszewska-Pazdrak B, Carney DH (2013) Systemic administration of thrombin peptide TP508 enhances VEGF-stimulated angiogenesis and attenuates effects of chronic hypoxia. J Vasc Res 50(3):186-196. https://doi.org/10.1159/000348250

94. Strnad J, McDonnell PA, Riexinger DJ et al (2006) NEMO binding domain of IKK-2 encompasses amino acids 735-745. J Molecular Recogn Interdisciplin J 19(3):227-233. https://doi. org/10.1002/jmr.766

95. Jimi E, Aoki K, Saito H et al (2004) Selective inhibition of $\mathrm{NF}-\kappa \mathrm{B}$ blocks osteoclastogenesis and prevents inflammatory bone destruction in vivo. Nat Med 10(6):617-624. https://doi. org/10.1038/nm1054

96. Jo J, Hong S, Choi WY et al (2014) Cell-penetrating peptide (CPP)-conjugated proteins is an efficient tool for manipulation 
of human mesenchymal stromal cells. Sci Rep 4:4378. https:// doi.org/10.1038/srep04378

97. Lee D, Park KS, Yoon GJ et al (2019) Identification of cellpenetrating osteogenic peptide from copine-7 protein and its delivery system for enhanced bone formation. J Biomed Mater Res A 107(11):2392-2402. https://doi.org/10.1002/jbm.a.36746

98. Visser R, Arrabal PM, Santos-Ruiz L et al (2014) A collagentargeted biomimetic RGD peptide to promote osteogenesis. Tissue Eng Part A 20(1-2):34-44. https://doi.org/10.1089/ten.TEA. 2012.0610

99. He B, Ou Y, Zhou A et al (2016) Functionalized d-form selfassembling peptide hydrogels for bone regeneration. Drug Des Dev Ther 10:1379. https://doi.org/10.2147/DDDT.S97530

100. Scholz M, Schleicher P, Sewing A et al (2013) Cyclic-RGD is as effective as rhBMP-2 in anterior interbody fusion of the sheep cervical spine. Spine 38(2):E59-E65. https://doi.org/10.1097/ BRS.0b013e31827ad2ff

101. Lin X, Patil S, Gao YG et al (2020) The bone extracellular matrix in bone formation and regeneration. Front Pharmacol 11(2):221222. https://doi.org/10.3389/fphar.2020.00757

102. Coelho PG, Teixeira HS, Marin C et al (2014) The in vivo effect of P-15 coating on early osseointegration. J Biomed Mater Res B Appl Biomater 102(3):430-440. https://doi.org/10.1002/jbm.b. 33020

103. Hamada Y, Nokihara K, Okazaki M et al (2003) Angiogenic activity of osteopontin-derived peptide SVVYGLR. Biochem Biophys Res Commun 310(1):153-157. https://doi.org/10.1016/j. bbrc.2003.09.001

104. Ceylan H, Kocabey S, Unal Gulsuner H et al (2014) Bone-like mineral nucleating peptide nanofibers induce differentiation of human mesenchymal stem cells into mature osteoblasts. Biomacromol 15(7):2407-2418. https://doi.org/10.1021/bm500248r

105. Wojtowicz AM, Shekaran A, Oest ME et al (2010) Coating of biomaterial scaffolds with the collagen-mimetic peptide GFOGER for bone defect repair. Biomaterials 31(9):2574-2582. https://doi.org/10.1016/j.biomaterials.2009.12.008

106. Gandavarapu NR, Alge DL, Anseth KS (2014) Osteogenic differentiation of human mesenchymal stem cells on $\alpha 5$ integrin binding peptide hydrogels is dependent on substrate elasticity. Biomater Sci 2(3):352-361. https://doi.org/10.1039/C3BM6 0149H

107. Zelenchuk LV, Hedge AM, Rowe PS (2015) Age dependent regulation of bone-mass and renal function by the MEPE ASARMmotif. Bone 79:131-142. https://doi.org/10.1016/j.bone.2015.05. 030

108. Lee J-A, Ku Y, Rhyu I-C et al (2010) Effects of fibrin-binding oligopeptide on osteopromotion in rabbit calvarial defects. J Periodontal Implant Sci 40(5):211. https://doi.org/10.5051/jpis.2010. 40.5.211

109. Schuler M, Hamilton DW, Kunzler TP et al (2009) Comparison of the response of cultured osteoblasts and osteoblasts outgrown from rat calvarial bone chips to nonfouling KRSR and FHRRIKA-peptide modified rough titanium surfaces. J Biomed Mater Res Part B Appl Biomater Offic J Soc Biomater Jap Soc Biomater Aust Soc Biomater Korean Soc Biomater 91(2):517-527. https://doi.org/10.1002/jbm.b.31425

110. Palchesko RN, Romeo JD, McGowan KA et al (2012) Increased osteoblast adhesion on physically optimized KRSR modified calcium aluminate. J Biomed Mater Res Part A 100(5):1229-1238. https://doi.org/10.1002/jbm.a.33303

111. Lee JY, Choo JE, Choi YS et al (2007) Characterization of the surface immobilized synthetic heparin binding domain derived from human fibroblast growth factor- 2 and its effect on osteoblast differentiation. J Biomed Mater Res Part A Off J Soc Biomater Jap Soc Biomater Aust Soc Biomater Korean Soc Biomater 83(4):970-979. https://doi.org/10.1002/jbm.a.31351
112. Chen Y, Webster TJ (2009) Increased osteoblast functions in the presence of BMP-7 short peptides for nanostructured biomaterial applications. J Biomed Mater Res Part A Off J Soc Biomater Jap Soc Biomater Aust Soc Biomater Korean Soc Biomater 91(1):296-304. https://doi.org/10.1002/jbm.a.32246

113. Yoshida W, Matsugami D, Murakami T et al (2019) Combined effects of systemic parathyroid hormone (1-34) and locally delivered neutral self-assembling peptide hydrogel in the treatment of periodontal defects: an experimental in vivo investigation. J Clin Periodontol 46(10):1030-1040. https://doi.org/10.1111/ jcpe. 13170

114. Jia S, Zhang SJ, Wang XD et al (2019) Calcitonin gene-related peptide enhances osteogenic differentiation and recruitment of bone marrow mesenchymal stem cells in rats. Exp Ther Med 18(2):1039-1046. https://doi.org/10.3892/etm.2019.7659

115. Zhao Z, Shao L, Zhao H et al (2011) Osteogenic growth peptide accelerates bone healing during distraction osteogenesis in rabbit tibia. J Int Med Res 39(2):456-463. https://doi.org/10.1177/ 147323001103900213

116. Cakarer S, Olgac V, Aksakalli N et al (2010) Acceleration of consolidation period by thrombin peptide 508 in tibial distraction osteogenesis in rats. Br J Oral Maxillofac Surg 48(8):633-636. https://doi.org/10.1016/j.bjoms.2009.11.009

117. Xu C-P, Chen Y, Sun HT et al (2019) Efficacy of NEMO-binding domain peptide used to treat experimental osteomyelitis caused by methicillin-resistant Staphylococcus aureus: an in-vivo study. Antimicrob Resist Infect Control 8(1):1-12. https://doi.org/10. 1186/s13756-019-0627-y

118. Suh JS, Lee JY, Choi YJ et al (2014) Intracellular delivery of cell-penetrating peptide-transcriptional factor fusion protein and its role in selective osteogenesis. Int J Nanomed 9:1153. https:// doi.org/10.2147/IJN.S55433

119. Kamerlin SC, Warshel A (2011) Multiscale modeling of biological functions. Phys Chem Chem Phys 13(22):10401-10411. https://doi.org/10.1039/c0cp02823a

120. Schlick T, Collepardo-Guevara R, Halvorsen LA et al (2011) Biomolecularmodeling and simulation: a field coming of age. Q Rev Biophys 44(2):191-228. https://doi.org/10.1017/S0033 583510000284

121. MacKerell AD Jr (2004) Empirical force fields for biological macromolecules: overview and issues. J Comput Chem 25(13):1584-1604. https://doi.org/10.1002/jcc.20082

122. Jorgensen WL, Tirado-Rives J (1996) Monte Carlo vs molecular dynamics for conformational sampling. J Phys Chem 100(34):14508-14513. https://doi.org/10.1021/jp960880x

123. Plimpton S (1995) Fast parallel algorithms for short-range molecular dynamics. J Comput Phys 117(1):1-19. https://doi. org/10.1006/jcph.1995.1039

124. Oostenbrink C, Villa A, Mark AE et al (2004) A biomolecular force field based on the free enthalpy of hydration and solvation: the GROMOS force-field parameter sets 53A5 and 53A6. J Comput Chem 25(13):1656-1676. https://doi.org/10.1002/jcc.20090

125. Wang J, Wolf RM, Caldwell JW et al (2004) Development and testing of a general amber force field. J Comput Chem 25(9):1157-1174. https://doi.org/10.1002/jcc.20035

126. Chandrasekhar I, Bakowies D, Glättli A et al (2005) Molecular dynamics simulation of lipid bilayers with GROMOS96: application of surface tension. Mol Simul 31(8):543-548. https://doi. org/10.1080/08927020500134243

127. Zhu X, Lopes PE, Mackerell AD Jr (2012) Recent developments and Applications of the CHARMM force fields. Wiley Interdiscip Rev Comput Mol Sci 2(1):167-185. https://doi.org/10.1002/ wcms.74

128. Lee OS, Stupp SI, Schatz GC (2011) Atomistic molecular dynamics simulations of peptide amphiphile self-assembly into 
cylindrical nanofibers. J Am Chem Soc 133(10):3677-3683. https://doi.org/10.1021/ja110966y

129. Lee OS, Cho V, Schatz GC (2012) Modeling the self-assembly of peptide amphiphiles into fibers using coarse-grained molecular dynamics. Nano Lett 12(9):4907-4913. https://doi.org/10.1021/ $\mathrm{nl} 302487 \mathrm{~m}$

130. Lee OS, Liu Y, Schatz GC (2012) Molecular dynamics simulation of $\beta$-sheet formation in self-assembled peptide amphiphile fibers. J Nanopart Res 14(8):936. https://doi.org/10.1007/ s11051-012-0936-z

131. Fu IW, Markegard CB, Chu BK et al (2014) Role of hydrophobicity on self-assembly by peptide amphiphiles via molecular dynamics simulations. Langmuir 30(26):7745-7754. https://doi. org/10.1021/la5012988

132. Quan C, Zhang Z, Liang P et al (2019) Bioactive gel self-assembled from phosphorylate biomimetic peptide: a potential scaffold for enhanced osteogenesis. Int J Biol Macromol 121:1054-1060. https://doi.org/10.1016/j.ijbiomac.2018.10.148

133. Rivas M, Del Valle LJ, Alemán C et al (2019) Peptide selfassembly into hydrogels for biomedical applications related to hydroxyapatite. Gels 5(1):14. https://doi.org/10.3390/gels5 010014

134. Eren ED, Tansik G, Tekinay AB et al (2018) Mineralized peptide nanofiber gels for enhanced osteogenic differentiation. ChemNanoMat 4(8):837-845. https://doi.org/10.1002/cnma. 201700354

135. Ando K, Imagama S, Kobayashi K et al (2018) Effects of a selfassembling peptide as a scaffold on bone formation in a defect. PLoS ONE 13(1):e0190833. https://doi.org/10.1371/journal. pone. 0190833

136. Tsukamoto J, Naruse K, Nagai Y et al (2017) Efficacy of a selfassembling peptide hydrogel, SPG-178-Gel, for bone regeneration and three-dimensional osteogenic induction of dental pulp stem cells. Tissue Eng Part A 23(23-24):1394-1402. https://doi. org/10.1089/ten.TEA.2017.0025

137. Gronthos S, Mankani M, Brahim J et al (2000) Postnatal human dental pulp stem cells (DPSCs) in vitro and in vivo. Proc Natl Acad Sci U S A 97(25):13625-13630. https://doi.org/10.1073/ pnas. 240309797

138. Gronthos S, Brahim J, Li W et al (2002) Stem cell properties of human dental pulp stem cells. J Dent Res 81(8):531-535. https:// doi.org/10.1177/154405910208100806

139. He B, Ou Y, Chen S et al (2017) Designer bFGF-incorporated d-form self-assembly peptide nanofiber scaffolds to promote bone repair. Mater Sci Eng C Mater Biol Appl 74:451-458. https://doi.org/10.1016/j.msec.2016.12.042

140. Zhou A, Chen S, He B et al (2016) Controlled release of TGFbeta 1 from RADA self-assembling peptide hydrogel scaffolds. Drug Des Devel Ther 10:3043-3051. https://doi.org/10.2147/ DDDT.S109545

141. Castillo Diaz LA, Elsawy M, Saiani A et al (2016) Osteogenic differentiation of human mesenchymal stem cells promotes mineralization within a biodegradable peptide hydrogel. J Tissue Eng 7:2041731416649789. https://doi.org/10.1177/2041731416 649789

142. Haggag EG, Elshamy AM, Rabeh MA et al (2019) Antiviral potential of green synthesized silver nanoparticles of Lampranthus coccineus and Malephora lutea. Int J Nanomed 14:6217. https://doi.org/10.2147/IJN.S214171

143. Mammadov R, Mammadov B, Guler MO et al (2012) Growth factor binding on heparin mimetic peptide nanofibers. Biomacromol 13(10):3311-3319. https://doi.org/10.1021/bm3010897

144. Kocabey S, Ceylan H, Tekinay AB et al (2013) Glycosaminoglycan mimetic peptide nanofibers promote mineralization by osteogenic cells. Acta Biomater 9(11):9075-9085. https://doi. org/10.1016/j.actbio.2013.07.007
145. Monsarrat P, Vergnes JN, Nabet $C$ et al (2014) Concise review: mesenchymal stromal cells used for periodontal regeneration: a systematic review. Stem Cells Transl Med 3(6):768-774. https:// doi.org/10.5966/sctm.2013-0183

146. Huang Z, Newcomb CJ, Bringas P Jr et al (2010) Biological synthesis of tooth enamel instructed by an artificial matrix. Biomaterials 31(35):9202-9211. https://doi.org/10.1016/j.bioma terials.2010.08.013

147. Elkassas D, Arafa A (2017) The innovative applications of therapeutic nanostructures in dentistry. Nanomedicine 13(4):15431562. https://doi.org/10.1016/j.nano.2017.01.018

148. Alkilzy M, Santamaria R, Schmoeckel J et al (2018) Treatment of carious lesions using self-assembling peptides. Adv Dent Res 29(1):42-47. https://doi.org/10.1177/0022034517737025

149. Li QL, Ning TY, Cao Y et al (2014) A novel self-assembled oligopeptide amphiphile for biomimetic mineralization of enamel. BMC Biotechnol 14(1):32. https://doi.org/10.1186/ 1472-6750-14-32

150. Nguyen PK, Gao W, Patel SD et al (2018) Self-assembly of a dentinogenic peptide hydrogel. ACS Omega 3(6):5980-5987. https://doi.org/10.1021/acsomega.8b00347

151. Wang R, Wang Q, Wang X et al (2014) Enhancement of nanohydroxyapatite bonding to dentin through a collagen/calcium dual-affinitive peptide for dentinal tubule occlusion. J Biomater Appl 29(2):268-277. https://doi.org/10.1177/0885328214523057

152. Simecek JW, Diefenderfer KE, Cohen ME (2009) An evaluation of replacement rates for posterior resin-based composite and amalgam restorations in US Navy and marine corps recruits. J Am Dent Assoc 140(2):200-209. https://doi.org/10.14219/jada. archive.2009.0134

153. Ferracane JL, Hilton TJ (2016) Polymerization stress-is it clinically meaningful? Dent Mater 32(1):1-10. https://doi.org/10. 1016/j.dental.2015.06.020

154. Ye Q, Spencer P, Yuca E et al (2017) Engineered peptide repairs defective adhesive-dentin interface. Macromol Mater Eng 302(5):1600487. https://doi.org/10.1002/mame.201600487

155. Galler KM, Cavender A, Yuwono V et al (2008) Self-assembling peptide amphiphile nanofibers as a scaffold for dental stem cells. Tissue Eng Part A 14(12):2051-2058. https://doi.org/10.1089/ ten.tea.2007.0413

156. Galler KM, Hartgerink JD, Cavender AC et al (2012) A customized self-assembling peptide hydrogel for dental pulp tissue engineering. Tissue Eng Part A 18(1-2):176-184. https://doi.org/ 10.1089/ten.TEA.2011.0222

157. Amosi N, Zarzhitsky S, Gilsohn E et al (2012) Acidic peptide hydrogel scaffolds enhance calcium phosphate mineral turnover into bone tissue. Acta Biomater 8(7):2466-2475. https://doi.org/ 10.1016/j.actbio.2012.04.003

158. Panek M, Antunović M, Pribolšan L et al (2019) Bone tissue engineering in a perfusion bioreactor using dexamethasoneloaded peptide hydrogel. Materials 12(6):919. https://doi.org/ 10.3390/ma12060919

159. Nonoyama T, Ogasawara H, Tanaka M et al (2012) Calcium phosphate biomineralization in peptide hydrogels for injectable bone-filling materials. Soft Matter 8(45):11531-11536. https:// doi.org/10.1039/C2SM26538A

160. Gulseren G, Yasa IC, Ustahuseyin O et al (2015) Alkaline phosphatase-mimicking peptide nanofibers for osteogenic differentiation. Biomacromol 16(7):2198-2208. https://doi.org/10.1021/ acs.biomac.5b00593

161. Castillo Diaz LA, Saiani A, Gough JE et al (2014) Human osteoblasts within soft peptide hydrogels promote mineralisation in vitro. J Tissue Eng 5:2041731414539344. https://doi.org/10. $1177 / 2041731414539344$

162. Çakmak S, Çakmak AS, Gümüşderelioğlu M (2013) RGDbearing peptide-amphiphile-hydroxyapatite nanocomposite bone 
scaffold: an in vitro study. Biomed Mater 8(4):045014. https:// doi.org/10.1088/1748-6041/8/4/045014

163. Kim SH, Hur W, Kim JE et al (2015) Self-assembling peptide nanofibers coupled with neuropeptide substance $P$ for bone tissue engineering. Tissue Eng Part A 21(7-8):1237-1246. https://doi. org/10.1089/ten.TEA.2014.0472

164. Lee SS, Huang BJ, Kaltz SR et al (2013) Bone regeneration with low dose BMP-2 amplified by biomimetic supramolecular nanofibers within collagen scaffolds. Biomaterials 34(2):452459. https://doi.org/10.1016/j.biomaterials.2012.10.005

165. Li K, Zhang Z, Li D et al (2018) Biomimetic ultralight, highly porous, shape-adjustable, and biocompatible 3D graphene minerals via incorporation of self-assembled peptide nanosheets. Adv Func Mater 28(29):1801056. https://doi.org/10.1002/adfm.20180 1056

166. Pan H, Hao S, Zheng Q et al (2013) Bone induction by biomimetic PLGA copolymer loaded with a novel synthetic
RADA16-P24 peptide in vivo. Mater Sci Eng, C 33(6):33363345. https://doi.org/10.1016/j.msec.2013.04.019

167. Wu G, Pan M, Wang X et al (2015) Osteogenesis of peripheral blood mesenchymal stem cells in self assembling peptide nanofiber for healing critical size calvarial bony defect. Sci Rep 5(1):1-12. https://doi.org/10.1038/srep16681

168. Yadav N, Chauhan MK, Chauhan VS (2020) Short to ultrashort peptide-based hydrogels as a platform for biomedical applications. Biomater Sci 8(1):84-100. https://doi.org/10.1039/C9BM0 $1304 \mathrm{~K}$

169. Abolmaali SS, Tamaddon AM, Salmanpour M et al (2017) Block ionomer micellar nanoparticles from double hydrophilic copolymers, classifications and promises for delivery of cancer chemotherapeutics. Eur J Pharm Sci 104:393-405. https://doi.org/10. 1016/j.ejps.2017.04.009

\section{Authors and Affiliations}

\section{Haniyeh Najafi ${ }^{1}$ Mahboobeh Jafari ${ }^{1}$. Ghazal Farahavar ${ }^{1}$. Samira Sadat Abolmaali ${ }^{1,2}$. Negar Azarpira ${ }^{3}$. Sedigheh Borandeh ${ }^{2,4} \cdot$ Raheleh Ravanfar $^{5}$ (B)}

Samira Sadat Abolmaali

abolmaali@sums.ac.ir; s.abolmaali@gmail.com

$\triangle$ Raheleh Ravanfar

raheleh@caltech.edu; rr699@cornell.edu

Haniyeh Najafi

najafi.han@gmail.com

Mahboobeh Jafari

jafari.mahboob@gmail.com

Ghazal Farahavar

gh_farahavar@yahoo.com

Negar Azarpira

negarazarpira@gmail.com

Sedigheh Borandeh

sedigheh.borandeh@aalto.fi
1 Pharmaceutical Nanotechnology Department, Shiraz University of Medical Sciences, 71345-1583 Shiraz, Iran

2 Center for Nanotechnology in Drug Delivery, Shiraz University of Medical Sciences, 71345-1583 Shiraz, Iran

3 Transplant Research Center, Shiraz University of Medical Sciences, Mohammad Rasoul-Allah Research Tower, 7193711351 Shiraz, Iran

4 Polymer Technology Research Group, Department of Chemical and Metallurgical Engineering, Aalto University, 02152 Espoo, Finland

5 Division of Chemistry and Chemical Engineering, California Institute of Technology, Pasadena, CA 91125, USA 